\title{
Implantes cocleares: aspectos tecnológicos e papel socioeconômico
}

Diego Tefili, Guillaume François Gilbert Barrault*, Alexandre André Ferreira, Júlio Apolinário Cordioli, Djones Vinicius Lettnin

Resumo Introdução: O grande número de deficientes auditivos faz da perda auditiva um sério problema social, econômico e de saúde pública. Próteses auditivas e implantes cocleares representam os principais dispositivos utilizados como paliativos por pessoas com deficiência auditiva, sendo que os implantes cocleares são muitas vezes a única opção nos casos de deficiência auditiva severa e profunda. Nesse artigo discute-se de maneira geral os diferentes aspectos envolvendo implantes cocleares, tanto de âmbito tecnológico como seu papel socioeconômico. Métodos: Baseado em dados do SUS, IBGE e outras fontes, um levantamento qualitativo e quantitativo é feito pela primeira vez especificamente para a população brasileira. O artigo discute ainda o estado da arte das tecnologias envolvidas no implante coclear, com base em literatura científica e informações de fabricantes, bem como as perspectivas para as próximas gerações de implantes cocleares. Conclusão: Há potencial e demanda para evoluções nos implantes atuais. A implantação precoce é benéfica para pacientes e sociedade, compensando os custos econômica e socialmente. No entanto, as políticas públicas de reabilitação necessitam se adequar para atender com eficácia à crescente população afetada pela deficiência auditiva.

Palavras-chave Implante coclear, Processamento de sinais, Deficiência auditiva severa e profunda, Impacto socioeconômico.

\section{Cochlear implants: technological aspects and socioeconomic role}

\begin{abstract}
Introduction: Due to the great number of affected people, hearing loss is considered a serious social, economic and public health problem. Hearing aids and cochlear implants are the primary devices used as palliatives for people with hearing loss, and cochlear implants are often the only option in cases of severe to profound hearing impairment. This paper covers both technological and socio-economic aspects of cochlear implant, which is considered as one of most recommended treatments to alleviate severe to profound hearing loss. Methods: Brazilian unified health system data is used to display qualitative and quantitative analysis impact on Brazilian population and government. A state-of-art review based on scientific literature and manufacturer data is provided, as well as perspectives for the next cochlear implant generation. Conclusion: There is potential and demand for evolutions in current implants. Early implantation is beneficial for patients and society, compensating the costs economic and socially. However, public programs need to adapt in order to efficiently attend the increasing affected population.
\end{abstract}

Keywords Cochlear implant, Signal processing, Severe to profound hearing loss, Socio-economic impact. 


\section{Introdução}

Próteses auditivas convencionais amplificam o som de acordo com a necessidade de cada paciente e o transmitem para a orelha média por meio de sistemas vibro-acústicos. Em pacientes cuja orelha interna encontra-se altamente danificada, resultando em perda auditiva severa ou profunda, próteses convencionais podem ser incapazes de restaurar a capacidade auditiva, limitando ou impossibilitando a fala e a linguagem (Cruz et al., 2012; Ilberg et al., 2011).

Nesse tipo de situação, uma possível solução é o estímulo direto do nervo auditivo ao longo da cóclea, localizada na orelha interna, por meio da aplicação de uma corrente elétrica. Ao dispositivo desenvolvido com este objetivo foi dado o nome de implante coclear (IC), também conhecido como "ouvido biônico" (Sarpeshkar et al., 2005), sendo considerado como a prótese neural de maior sucesso até o momento (Wilson e Dorman, 2008). Os primeiros ICs foram aprovados para uso comercial na década de 1980 pela Food and Drug Administration (FDA) (Food..., 1984), órgão controlador de equipamentos médicos dos Estados Unidos da América. Atualmente, o IC é considerado o estado-da-arte no tratamento de pacientes com perda auditiva de severa a profunda (Oshima et al., 2010). Estima-se que, no mundo, 219 mil pessoas tenham recebido um IC até 2010 (National..., 2011).

Este artigo visa apresentar sucintamente quem são os candidatos à utilização de implantes cocleares; mensurar o impacto socioeconômico das deficiências auditivas e a importância de uma implantação precoce; descrever a tecnologia envolvida no IC; e, finalmente, vislumbrar o futuro dos ICs e suas consequências. O texto sintetiza a complexidade tecnológica e os benefícios relacionados ao dispositivo, abordando temas sociais e econômicos, bem como aspectos referentes à engenharia.

\section{Sistema auditivo humano}

Os principais componentes do sistema auditivo periférico humano podem ser divididos em orelhas externa, média e interna. Na orelha externa, localiza-se o pavilhão auricular, responsável por concentrar a energia acústica na entrada do canal auditivo externo e facilitar a localização das fontes sonoras. O canal auditivo externo constitui-se de um duto com aproximadamente $2,5 \mathrm{~cm}$ e que possui a primeira frequência natural em torno de $3,5 \mathrm{kHz}$, o que colabora para a maior sensibilidade do sistema auditivo nessa faixa de frequência (Berne et al., 2010).

No final do canal auditivo externo, encontra-se a membrana timpânica e, internamente, os três ossículos que formam a orelha média (martelo, bigorna e estribo), os quais são responsáveis por conduzir as vibrações da membrana timpânica à orelha interna. A orelha média atua como um adaptador de impedâncias entre o ar e o líquido da cóclea, maximizando a transmissão da energia acústica. Para frequências entre $300 \mathrm{~Hz}$ e $3 \mathrm{kHz}$, esse sistema proporciona um casamento de impedâncias de cerca de 50 a $75 \%$. Ainda na orelha média, existe um par de músculos que se contrai quando a amplitude do som alcança níveis elevados, funcionando como um controlador automático de ganho e protegendo as estruturas internas contra danos.

A orelha interna é formada pela cóclea e pelos canais semicirculares. Enquanto os canais semicirculares estão relacionados ao equilíbrio, a cóclea é o principal órgão do sistema auditivo, transformando a vibração dos ossículos em sinais elétricos a serem enviado ao cérebro. A cóclea possui a forma de um duto em espiral, o qual é divido internamente em três seções (escala timpânica, escala média e escala vestibular), sendo constituída em sua maior parte por tecido ósseo. As diferentes seções da cóclea (escalas) encontram-se cheias de líquidos, os quais são responsáveis por transmitir as vibrações do estribo para a membrana basilar. A membrana basilar separa as escalas vestibular e média da escala timpânica e é composta por fibras com diferentes graus de elasticidade. A diferença de tamanho e elasticidade entre as fibras que compõem a membrana basilar faz com que diferentes regiões vibrem de acordo com a frequência da onda sonora incidente na orelha, de modo que sons agudos excitam a região basal da cóclea, e sons graves, a região apical (Guyton e Hall, 2006).

Esta associação entre frequências e posições é conhecida como teoria da codificação espacial da frequência ou tonotopia coclear (Zeng, 2004) e equivale a uma transformação espectro-espacial.

A vibração da membrana basilar aciona células ciliadas (estereocílios) distribuídas ao longo da mesma. Uma vez acionadas, estas células liberam neurotransmissores para o gânglio espiral, a porção do nervo auditivo localizada no interior da cóclea. O nervo auditivo envia então impulsos elétricos para o córtex auditivo no cérebro, e este, por sua vez, decodifica os sinais e interpreta-os como audição (Guyton e Hall, 2006). A Figura 1 associa cada estrutura da orelha à sua função no sistema auditivo.

\section{Deficiências auditivas}

A perda de sensibilidade auditiva pode ser causada por inconformidades em diferentes componentes do sistema auditivo e pode ter um padrão irregular ao longo do espectro de frequências audíveis. A avaliação do grau de perda auditiva e sua distribuição na frequência são realizadas através do teste denominado de audiometria, 


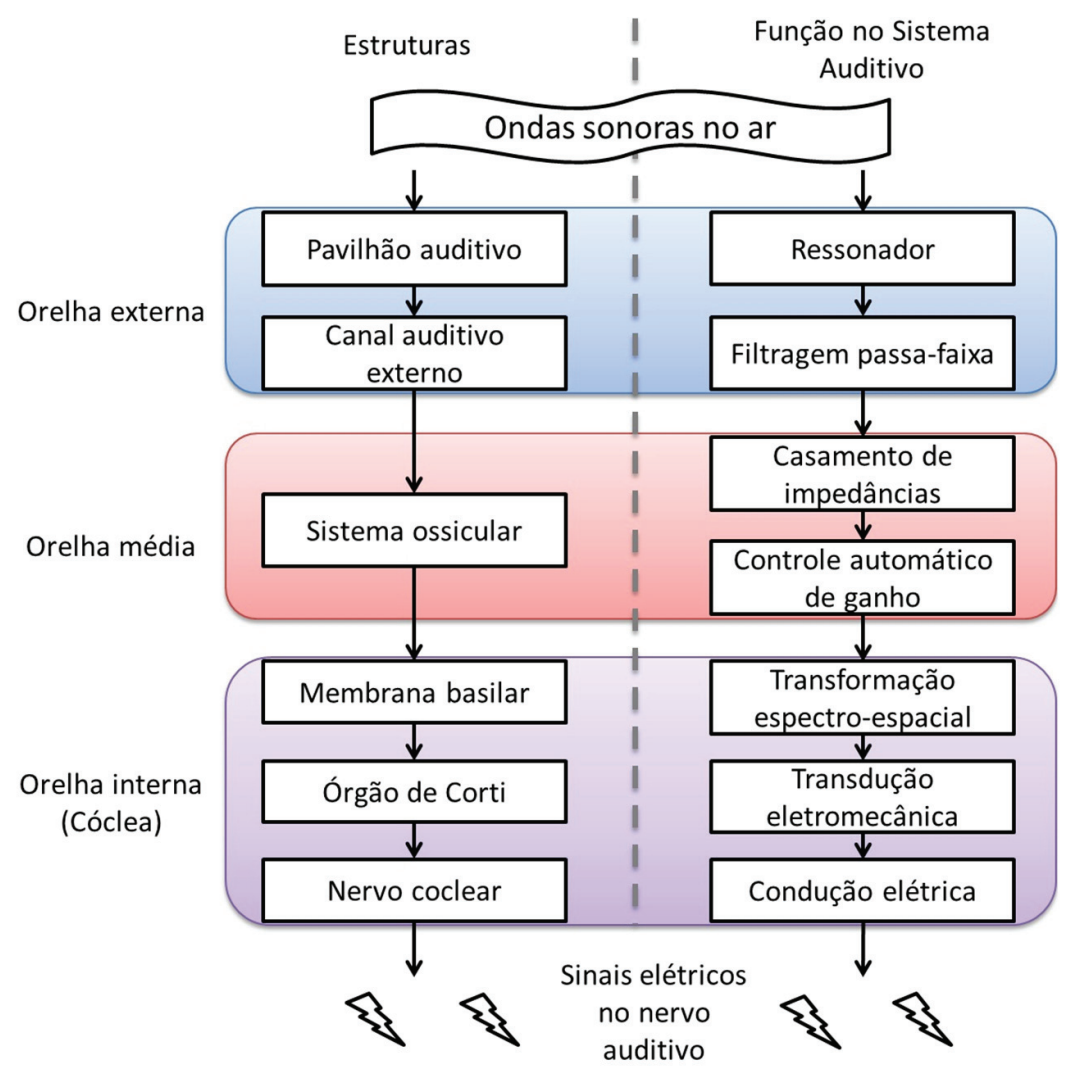

Figura 1. Diagrama de blocos parcial do sistema auditivo periférico e as funções de cada estrutura.

Figure 1. Partial block diagram of the peripheral auditory system and the functions of each structure.

sendo o audiômetro o equipamento utilizado durante o teste. Em uma audiometria, o paciente recebe tons puros com amplitudes variáveis através de um fone de ouvido e sinaliza quando percebe ou não o som. $\mathrm{O}$ teste é normalmente realizado para 8 a 10 frequências diferentes e fornece os limiares em decibel nível de audição (dB NA), o qual corresponde a uma calibração da escala decibel nível de pressão sonora (dB NPS) de forma a considerar um padrão de normalidade auditiva, tal que $0 \mathrm{~dB}$ NA corresponda ao menor nível de audição modal para adultos jovens auditivamente normais (Costa et al., 2006).

O grau de perda auditiva pode ser determinado a partir média dos limiares entre 500 e $4.000 \mathrm{~Hz}$. A Tabela 1 apresenta uma das classificações utilizadas para adultos. De uma forma geral, dificuldades de interação social podem ser significativas para pessoas com perdas auditivas maiores que $40 \mathrm{~dB}$ NA (Shield, 2006).

Pode-se dividir as deficiências auditivas em três tipos: condutiva, neurossensorial e mista. A perda auditiva de condução acontece quando há irregularidades nos componentes da orelha média e pode ser provocada por infecções ou doenças hereditárias. Em alguns casos, pode ser corrigida por substituição das partes afetadas por próteses. Já a perda auditiva neurossensorial é caracterizada pela destruição dos estereocílios, lesão na cóclea ou danos no sistema neural. A deficiência mista ocorre quando há perda significativa dos dois tipos anteriores. A perda de sensibilidade em altas frequências por danos à base da cóclea costuma ocorrer, em diferentes níveis, em quase todas as pessoas em idade avançada. Por outro lado, sons muito intensos, especialmente os mais graves, são danosos ao órgão de Corti presente na cóclea, podendo levar à perda em baixas frequências, em caso de exposição prolongada. Alguns antibióticos podem afetar também o órgão de Corti, diminuindo sua sensibilidade. Neste caso, os danos geralmente afetam toda a extensão do órgão, causando deficiência para todas as frequências (Guyton e Hall, 2006).

De uma forma geral, a causa mais comum de perda auditiva é a destruição de células ciliadas devido à exposição a níveis sonoros excessivamente altos (Berne et al., 2010; Fettiplace e Hackney, 2006). Pessoas com deficiência auditiva leve a moderadamente 
Tabela 1. Classificação da Perda Auditiva - Adaptado de CFFa (Conselho..., 2009) e WHO (World..., 2013a).

Table 1. Hearing loss grades - Adapted from CFFa (Conselho..., 2009) e WHO (World..., 2013a).

\begin{tabular}{llll}
\hline Grau de Perda Auditiva & Nível (dB NA) & \multicolumn{1}{c}{ Desempenho } & \multicolumn{1}{c}{ Recomendações } \\
\hline Audição normal & 25 ou menos & $\begin{array}{l}\text { Audição normal, capaz de ouvir } \\
\text { sussurros. }\end{array}$ & $\begin{array}{l}\text { Exame de acompanhamento. } \\
\text { Leve }\end{array}$ \\
\hline Capaz de ouvir e repetir palavras a 40 & $\begin{array}{l}\text { Próteses auditivas podem ser } \\
\text { aconselháveis. Se a perda for condutiva } \\
\text { distância. }\end{array}$ & $\begin{array}{l}\text { ou moz normal a 1 m de } \\
\text { indicado. }\end{array}$ \\
\hline Moderada & 41 a 55 & $\begin{array}{l}\text { Capaz de ouvir e repetir palavras cirúrgico pode ser } \\
\text { faladas em voz elevada a 1 m de } \\
\text { distância. }\end{array}$ & $\begin{array}{l}\text { Próteses auditivas são recomendadas. Se a } \\
\text { perda for condutiva ou mista, tratamento } \\
\text { cirúrgico pode ser indicado. }\end{array}$ \\
\hline Moderadamente severa & 56 a 70 & $\begin{array}{l}\text { Capaz de ouvir e repetir palavras } \\
\text { faladas em voz elevada a 1 m de } \\
\text { distância. }\end{array}$ & $\begin{array}{l}\text { Próteses auditivas são recomendadas. Se a } \\
\text { perda for condutiva ou mista, tratamento } \\
\text { cirúrgico pode ser indicado. }\end{array}$ \\
\hline Severa & 71 a 90 & $\begin{array}{l}\text { Capaz de ouvir algumas palavras } \\
\text { quando gritadas na orelha com } \\
\text { menor perda. }\end{array}$ & $\begin{array}{l}\text { Próteses auditivas são necessárias. } \\
\text { Implante coclear pode ser indicado. }\end{array}$ \\
\hline Profunda & 91 ou mais & Incapaz de ouvir voz gritada. & $\begin{array}{l}\text { Próteses auditivas são necessárias. } \\
\text { Implante coclear pode ser indicado. }\end{array}$ \\
\hline
\end{tabular}

severa (até $70 \mathrm{~dB}$ NA (Mohr et al., 2000)) podem utilizar uma próteses auditiva convencional. Para pacientes com perda auditiva neurossensorial severa ou profunda (acima de $70 \mathrm{~dB}$ NA), o ganho necessário da prótese auditiva pode ser impraticável, pois a amplitude do sinal de saída se aproxima ou ultrapassa o limiar de conforto (aproximadamente $120 \mathrm{~dB}$ NA), provocando dor (Ching et al., 1998). Outra consequência desta proximidade dos limiares é a redução da faixa dinâmica, que pode chegar a ser menor que $20 \mathrm{~dB}$ (Zeng et al., 2002). Em alguns casos, a quantidade de estereocílios pode ser tão pequena que o som não é percebido com qualquer amplificação (Heiduschka e Thanos, 1998).

Se a cóclea ou o nervo auditivo forem significativamente danificados, a perda auditiva é permanente, e não existem tratamento ou paliativos aplicáveis atualmente. No entanto, caso o nervo auditivo esteja razoavelmente intacto, uma possível solução é a estimulação elétrica dos receptores neurais localizados na cóclea (Shepherd et al., 1983) através de um implante coclear. Diversas pesquisas e relatos comprovam a eficácia dos implantes cocleares através dos altos índices de reconhecimento de voz na ausência de ruído (Budenz et al., 2011; Davidson et al., 2011; Robinson et al., 2012; Skarzynski et al., 2012).

\section{Candidatos a um implante Coclear}

O Ministério da Saúde estabelece os seguintes critérios para indicação de implantes cocleares (Brasil, 1999):

- Em adultos:

a) pessoas com surdez neurossensorial profunda bilateral com código linguístico estabelecido (casos de surdez pós-lingual ou de surdez pré-lingual, adequadamente reabilitados);

b) ausência de benefício com prótese auditiva (menos de $30 \%$ de discriminação vocal em teste com sentenças);

c) adequação psicológica e motivação para o uso de implante coclear.

- Em crianças:

a) experiência com prótese auditiva, durante pelo menos três meses;

b) incapacidade de reconhecimento de palavras em conjunto fechado;

c) família adequada e motivada para o uso do implante coclear;

d) condições adequadas de reabilitação na cidade de origem.

Desde 2012, planos de saúde privados no Brasil são obrigados a oferecer cobertura de implante coclear uni ou bilateral. Neste âmbito, os requisitos básicos são perda auditiva neurossensorial severa ou profunda bilateral; motivação adequada da família (para menores de 12 anos ou deficientes pós-linguais) ou do paciente (se maior de 12 anos ou deficiente pré-lingual) para o uso do implante coclear e para o processo de reabilitação fonoaudiológica. Para crianças até 7 anos, é exigida ainda experiência com uso de próteses auditivas por um período mínimo de 3 meses após diagóstico de perda auditiva severa. Maiores de 12 anos devem ter resultado igual ou menor que $50 \%$ de reconhecimento de sentenças em formato aberto com uso de prótese auditiva em ambas as orelhas; e, em caso de deficiência pré-lingual, presença de código 
linguístico estabelecido e reabilitação adequada pelo método oral (Agência..., 2010).

\section{Importância da implantação precoce}

Todas as crianças podem ter sua audição avaliada, até mesmo recém nascidos com apenas minutos de vida (Morton e Nance, 2006). Nos Estados Unidos, mais de $95 \%$ dos recém-nascidos são examinados pouco depois do parto (Russ et al., 2010). A avaliação pode ser feita por meio da análise do potencial evocado auditivo de tronco encefálico, que utiliza ondas eletrofisiológicas para verificar a integridade neural das vias auditivas até o tronco encefálico. A resposta neural é captada por eletrodos de superfície alocados na cabeça do paciente (Kollmeier et al., 2009).

Outro método, conhecido no Brasil como Teste da Orelhinha (Hilú e Zeigelboim, 2007), faz uso das emissões otoacústicas evocadas da orelha interna. Este método capta energia sonora emitida pelas células ciliadas da cóclea em resposta a impulsos sonoros (Doyle et al., 1997; Sokol e Hyde, 2002). A medição é realizada através do canal auditivo. Ambos os métodos são não invasivos e de fácil aplicação (Hilú e Zeigelboim, 2007), o que permite a identificação de crianças com poucos meses de vida como possíveis candidatas a receber um implante coclear.

Pesquisas demonstram que crianças com perda auditiva profunda que recebem um implante coclear precocemente tem desempenho significativamente melhor do que as que o recebem o implante mais tardiamente (Holt e Svirsky, 2008; Nicholas e Geers, 2006). Mesmo perdas leves podem resultar em atraso na aprendizagem da fala e no domínio da linguagem, além de problemas sócio emocionais, comportamentais e, consequentemente, afetar o desempenho escolar (Magalhães et al., 2007, Yoshinaga-Itano e Apuzzo, 1998; Yoshinaga-Itano et al., 1998). Por outro lado, a maioria das crianças com perda auditiva profunda implantadas e assistidas por profissionais podem tornarse tão capacitadas quanto crianças com audição normal na mesma idade (Geers et al., 2009; Svirsky et al., 2004; Teagle e Moore, 2002).

Há evidências de que a audição é a ferramenta mais eficaz para a aprendizagem da linguagem falada, leitura e habilidades cognitivas. A experiência de ouvir na infância é fundamental para o desenvolvimento da fala e leitura (Cole e Flexer, 2007). Isto enfatiza a importância de se equipar os deficientes auditivos o quanto antes com um aparelho auditivo ou implante coclear, a fim de melhorar as condições destes para se tornarem ativos e produtivos na sociedade.

Durante as primeiras semanas de vida, neurônios produzem axônios em excesso em muitas regiões do cérebro. Caso os novos axônios não sejam estimulados, ou não consigam se conectar a outras células, desaparecerão em poucas semanas. Além disso, um neurônio inteiro pode desaparecer caso não haja conectividade suficiente. Por exemplo, se um animal recém-nascido for vendado por muitas semanas, neurônios do córtex cerebral visual irão degenerar, e a visão do olho coberto jamais se desenvolverá (Guyton e Hall, 2006). Da mesma forma, uma criança que não receber estímulo auditivo terá seu córtex auditivo permanentemente atrofiado. A máxima neuroplasticidade do sistema auditivo central ocorre do nascimento até aproximadamente 3,5 anos de idade (Sharma et al., 2002).

Gilley et al. (2008) destacam a importância da implantação precoce usando um eletroencefalograma de alta densidade para mapear as áreas de ativação cerebral (em resposta a um som de fala) de três grupos distintos: crianças com audição normal; crianças de mesma idade que tenham recebido implante antes dos 3,5 anos de idade; e crianças que tenham sido implantadas após os 7 anos. Como esperado, ouvintes normais mostraram ativação bilateral das áreas auditivas corticais. Como pode ser visto na Figura 2, em crianças implantadas precocemente, há ativação das áreas corticais auditivas contralaterais ao seu implante. Esta ativação mostra-se muito semelhante à dos ouvintes normais. Entretanto, indivíduos implantados mais tardiamente $(>7$ anos de idade) exibiram ativação consideravelmente mais superficial e fora destas áreas.

\section{Aspectos Socioeconômicos}

Segundo a Organização Mundial da Saúde (OMS), em 2012, o número de pessoas com deficiência auditiva no mundo ultrapassava 360 milhões (World..., 2013b). O Censo 2010, realizado pelo Instituto Brasileiro de Geografia e Estatística, contabilizou 9,8 milhões de brasileiros com deficiência auditiva, o que representa $5,2 \%$ da população brasileira. Deste total, 2,6 milhões eram surdos e 7,2 milhões apresentavam grande dificuldade para ouvir (Instituto..., 2010). A população de baixa renda é mais afetada pela deficiência auditiva, por falta de acesso à prevenção, cuidados médicos e incapacidade financeira para compra e manutenção de próteses adequadas (World..., 2012).

Um dos principais problemas decorrentes da deficiência auditiva é a diminuição da inteligibilidade da fala, impondo ao deficiente dificuldade de comunicação. Apesar de muitas vezes o deficiente escutar parcialmente, a menor inteligibilidade do som pode não ser suficiente para o entendimento. A capacidade de se comunicar através da fala desempenha um papel essencial na organização 


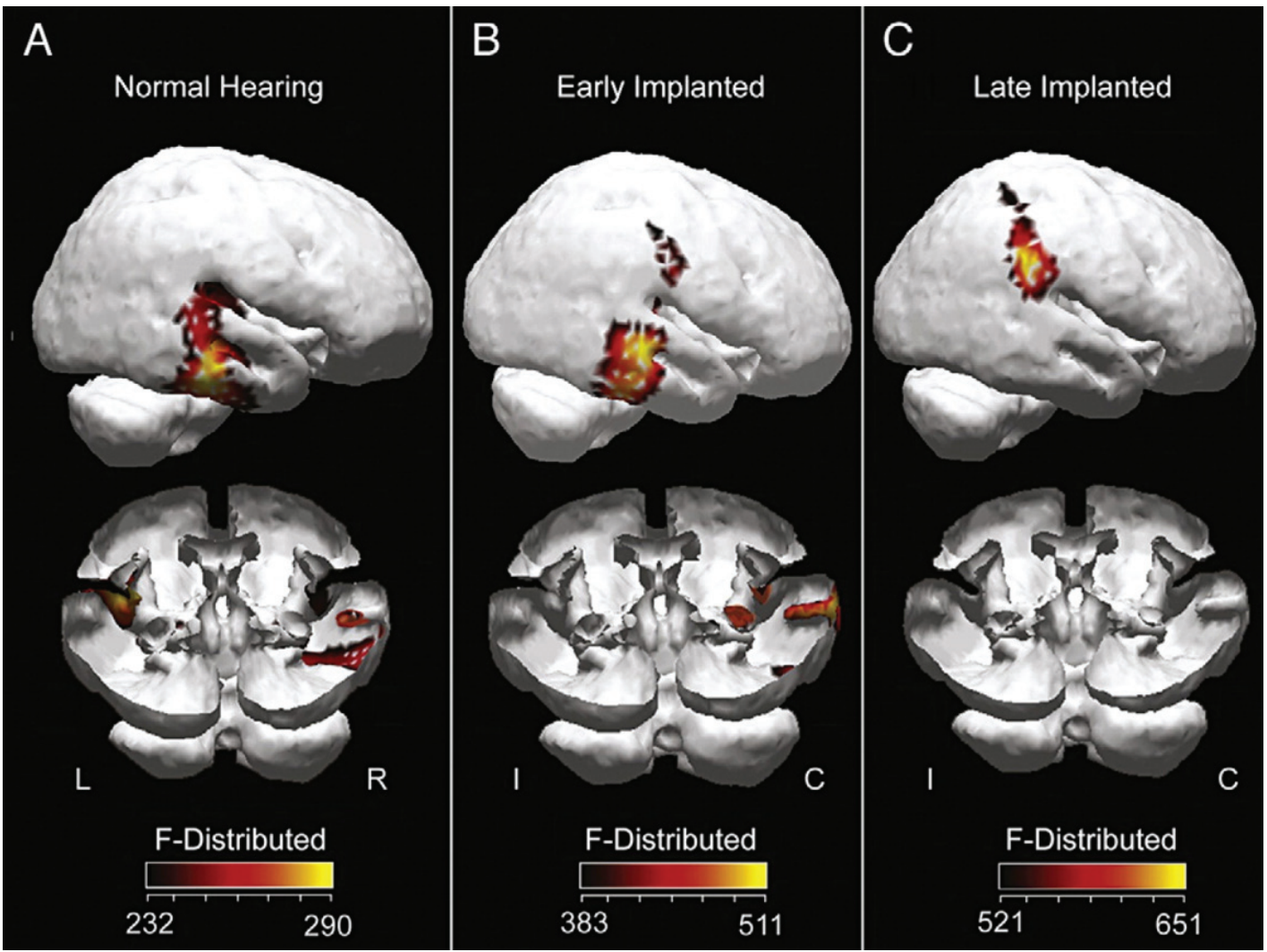

Figura 2. Ativação de áreas corticais em resposta à estimulação sonora na audição normal (esquerda), implantação precoce (centro), e implantação mais tardia (direita). Ouvintes normais e crianças implantadas precocemente mostram ativação nas áreas corticais auditivas. A atividade em implantados tardiamente é superficial e fora das áreas corticais auditivas (Gilley et al., 2008).

Figure 2. Activation of cortical areas in response to sound stimulation in normal hearing (left), early implanted (center), and later implanted (right). Normal listeners and early implanted show activation in auditory cortical areas. The activity in later implanted is superficial and out of auditory cortical areas (Gilley et al., 2008).

perceptual, na recepção e estruturação de informações, na aprendizagem e nas interações sociais do ser humano. Essa dificuldade na comunicação pode levar a pessoa ao isolamento social, diminuindo sua qualidade de vida. Os efeitos da deficiência auditiva podem ser ainda piores para as crianças. A incapacidade ou dificuldade na comunicação através da fala diminui significativamente sua capacidade de desenvolvimento e aprendizado (World..., 2013b; Most, 2004).

Perda auditiva é uma das deficiências mais comuns no mundo, figurando entre as doenças mais onerosas à sociedade, segundo a OMS. A previsão é de que deficiência auditiva avance da $15^{\text {a }}$ posição em 2004 para o $7^{\text {a }}$ lugar no encargo mundial de doenças até 2030 (Mathers et al., 2008). Uma das consequências econômicas diretas é que trabalhadores com deficiência auditiva não tratada podem sofrer prejuízo salarial, segundo pesquisa realizada nos Estados Unidos (Mohr et al., 2000). $\mathrm{O}$ estudo relata que pessoas que desenvolvem perda auditiva severa ou profunda antes da aposentadoria podem ter remuneração entre 30 e $40 \%$ menor que seus colegas com audição normal.

Segundo estimativas do Centro de Controle e Prevenção de Doenças dos Estados Unidos, cada deficiente auditivo custa em média US\$ 417 mil ao longo da vida (Honeycutt et al., 2004); e quando crianças com perda auditiva não são identificadas e não recebem intervenção precoce, a educação especial dedicada às mesmas tem um custo equivalente ao dobro da educação regular (Limb et al., 2010). Em caso de perda auditiva de severa a profunda adquirida antes do desenvolvimento da linguagem, o custo total ao longo da vida chega a aproximadamente US\$ 1 milhão por indivíduo, distribuído entre os familiares e o governo (Mohr et al., 2000).

$\mathrm{O}$ processo de perda auditiva neurossensorial devido à morte das células ciliadas na cóclea está diretamente ligado ao processo de envelhecimento (Guyton e Hall, 2006). Segundo o Censo 2010, a maior parcela dos deficientes no Brasil encontra-se nos grupos de idade avançada (Instituto..., 2010). 
Em países em desenvolvimento como o Brasil, com o aumento da idade média da população, o número de pessoas com perda auditiva deve ser cada vez maior. Além disso, hábitos de vida modernos, como frequentar ambientes com som alto e utilizar fones de ouvido em nível elevado, levam a um processo de perda auditiva acelerado (Tung e Chao, 2013; Vogel et al., 2011).

Apesar das grandes limitações impostas pela perda auditiva, diagnóstico e tratamento precoces permitem reduzir os impactos negativos decorrentes desta deficiência (Oshima et al., 2010). Estudos realizados pelo Centro de Avaliação de Programas de Saúde Australiano (CHPE) (Carter e Hailey, 1999) e pelo Serviço Nacional de Saúde Britânico (Bond et al., 2009; National..., 2009) sugerem que crianças com perda auditiva profunda usuárias de implante coclear estão mais propensas a serem educadas em uma escola regular do que as não implantadas, além de conseguir melhor desempenho escolar. Outro estudo, realizado nos Estados Unidos (Cheng et al., 2000) considerou custos relacionados a dispositivo, cirurgia, treinamento para reabilitação, substituição de equipamentos, consultas clínicas regulares, baterias descartáveis, além do nível de renda estimado para o indivíduo e sua acessibilidade a escolas regulares e profissionalizantes. Tendo englobado uma extensa análise de custo-benefício, a pesquisa concluiu que a implantação em crianças com perda auditiva profunda tem efeito positivo tanto na qualidade de vida do paciente quanto no balanço de custos para a sociedade. A longo prazo, os custos da implantação são compensados pelo montante economizado em educação especial para pacientes com perda auditiva profunda e pelo rendimento econômico do implantado (Robertson e Flexer, 1993).

\section{Situação Brasileira}

No Brasil, o Sistema Único de Saúde (SUS) fornece gratuitamente serviço de implantação coclear unilateral desde 1999. Nesse período, 2.800 pessoas foram implantadas, sendo que, apenas em 2012, foram realizadas 644 cirurgias (Brasil, 2013a). Estes e outros números da saúde no Brasil podem ser obtidos através do DATASUS, um banco de dados de acesso público com indicadores e informações financeiras do SUS.

O valor médio dispendido pelo SUS para cada implante coclear é de aproximadamente R $\$ 46$ mil, dos quais cerca de $\mathrm{R} \$ 44$ mil destinam-se à compra do dispositivo (Brasil, 2013b), e o restante, ao procedimento cirúrgico. $\mathrm{O}$ alto preço dos implantes cocleares deve-se principalmente ao fato que $100 \%$ dos mesmos são importados, visto que não há fabricantes nacionais com domínio dessa tecnologia. Somente em 2012, a despesa nacional com compra de ICs foi de R \$28,47 milhões. O gráfico da Figura 3 representa os gastos do SUS referentes à compra de próteses importadas para implantação. No total, o valor empregado em implantes cocleares pelo SUS nos últimos cinco anos chega a $\mathrm{R} \$ 127,12$ milhões.

Apesar de fornecer o dispositivo e a cirurgia, até a presente data, o SUS não se responsabiliza pela manutenção do IC. Assim, ficam a cargo do paciente todas as despesas decorrentes do uso do dispositivo, que incluem reposição de peças defeituosas ou danificadas e troca periódica de baterias. Grande parte dos candidatos é de famílias de baixa renda, desprovidos de condições de manter os componentes externos do IC. Este aspecto social pode influenciar na decisão dos profissionais da saúde ao fazer a escolha dos candidatos. Dada a subjetividade dos critérios de seleção (Brasil, 1999) quanto à motivação e a adequação para a implantação, deficientes com condição financeira precária podem ser excluídos do processo (Mussa et al., 2010). Devido ao número insuficiente de aparelhos disponibilizados, os profissionais podem ter receio de que ICs implantados em pacientes de baixa renda não sejam utilizados por falta de manutenção e baterias, conforme apontado por Gontijo (2012). O referido trabalho levanta questionamentos sobre a eficácia da atual estratégia brasileira de inclusão social destes deficientes, indicando a existência de problemas pouco relatados, além de apontar para a carência de pesquisas relacionadas ao acompanhamento pós-operatório.

Em resposta a esta situação, surgiu a Associação dos Deficientes Auditivos, Pais, Amigos e Usuários de Implante Coclear, instituição filantrópica com o objetivo de auxiliar os usuários na compra de acessórios e consertos (Associação..., 2013). Existe ainda outra reação da população envolvida, na forma de uma petição em apoio a uma ação civil pública

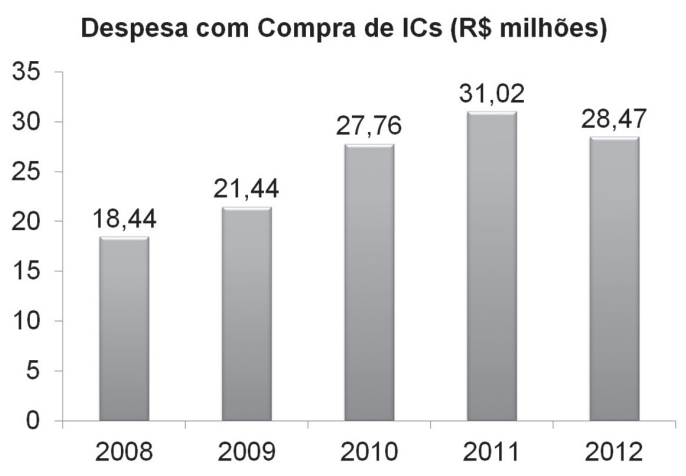

Figura 3. Despesas do SUS com Implantes Cocleares (Brasil, 2013a). Figura 3. Brazilian Unified Health System expenses on cochlear implants (Brasil, 2013a). 
solicitando que o SUS estenda seu programa de saúde auditiva de modo a prover a manutenção dos ICs (Petição Pública, 2013).

\section{Funcionamento do Implante Coclear}

A função básica do implante coclear é de estimular eletricamente as fibras nervosas do nervo auditivo ao longo da cóclea de acordo com o campo acústico externo ao paciente, provocando sensações capazes de ser interpretadas pelo cérebro como audição. Para tal, o som ambiente deve ser convertido em sinal elétrico e adaptado para corresponder aos estímulos necessários na cóclea. A captura do áudio é feita tipicamente através de um ou dois microfones, localizados na parte externa da prótese, afixada na orelha, em um sistema equivalente ao aparelho auditivo retro auricular (Behind The Ear - BTE). O esquema típico de um IC é ilustrado na Figura 4.

O sinal proveniente do(s) microfone(s) é enviado para um processador digital de sinais (Digital Signal Processor - DSP) (Eddington et al., 2001), no qual é dividido em bandas de frequências. Cada banda é manipulada independentemente de acordo com as necessidades de cada paciente. Do sinal obtido em cada banda, é extraído um sinal útil (teoricamente livre de ruído), o qual é codificado e enviado por radiofrequência através da pele para um receptor implantado cirurgicamente no crânio (Cochlear Ltd., 2009).

O dispositivo implantado recebe o sinal externo e gera os estímulos elétricos a serem aplicados na cóclea por um grupo de eletrodos. A posição de cada eletrodo determina a faixa de frequência induzida pelo mesmo de acordo com a tonotopia coclear (Loizou, 1998). Além dos contatos estimuladores, existem 1 ou 2 eletrodos de referência, que não estão ligados a fontes de corrente, mas sim de tensão, a fim de induzir uma diferença de potencial na direção desejada (Carlson et al., 2012). A sequência de estágios de processamento está ilustrada na Figura 5.

A organização do sistema auditivo humano resulta na modificação do sinal acústico incidente ao longo da cadeia de componentes do sistema auditivo até que o mesmo seja convertido em sinal elétrico na cóclea, conforme mostrado na Figura 1. Isto pode ser interpretado como a aplicação de diferentes tratamentos de sinal realizados no sinal acústico original. Esses processos precisam ser mimetizados pelos aparelhos auditivos e/ou implantes cocleares, que aplicam vários estágios de processamento para transformar o sinal captado pelo microfone em informação inteligível. Os principais algoritmos utilizados são filtragem, controle automático de ganho, controle de diretividade, redução de ruído e compressão da faixa dinâmica (Wide Dynamic Range Compression - WDRC) (Hamacher et al., 2005). Além destes processos, em implantes cocleares, o sinal obtido precisa passar ainda por estágios de codificação que serão descritos adiante.

\section{Aprimoramento do sinal}

Conhecendo-se as características físicas e espectrais típicas da fala e do ruído (sinal acústico interpretado como indesejado), pode-se aprimorar o sinal original, extraindo-se somente a informação de interesse. Em sistemas com dois microfones, é possível aplicar o algoritmo direcional (Figura 5A), o qual faz uso da

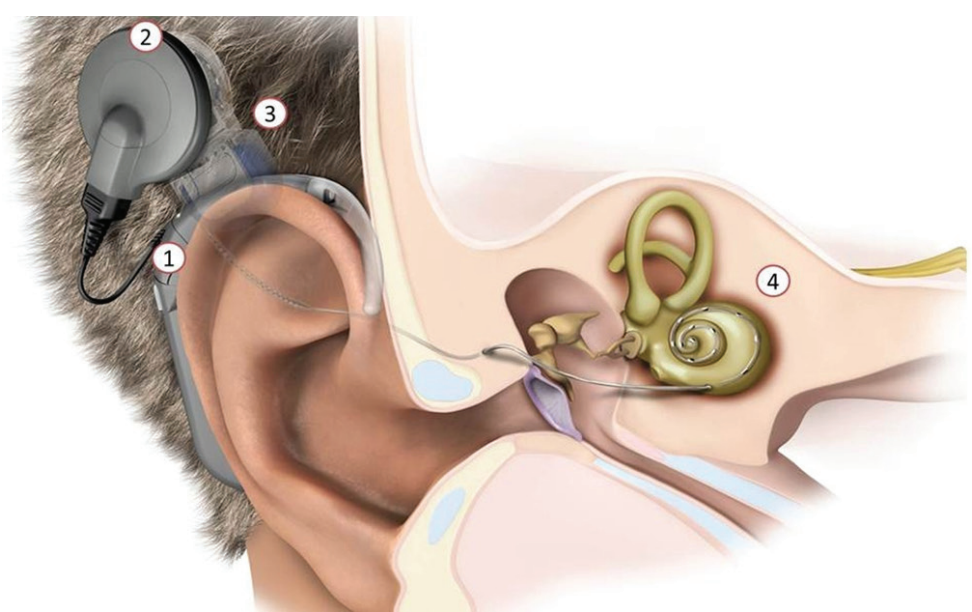

Parte Externa

(1) Processador externo

(2) Antena externa

Parte Interna

(3) Receptor implantado

(4) Eletrodos

Figura 4. Esquema genérico de implante coclear. Adaptado de MED-EL (2012b). É importante salientar que não existe ligação direta entre a parte externa e a implantada, ou seja, não há abertura na pele.

Figure 4. Generic arrangement of a cochlear implant. Adapted from MED-EL (2012b). Note the absence of direct connection between the internal and external parts, i.e., there is no opening on the skin. 

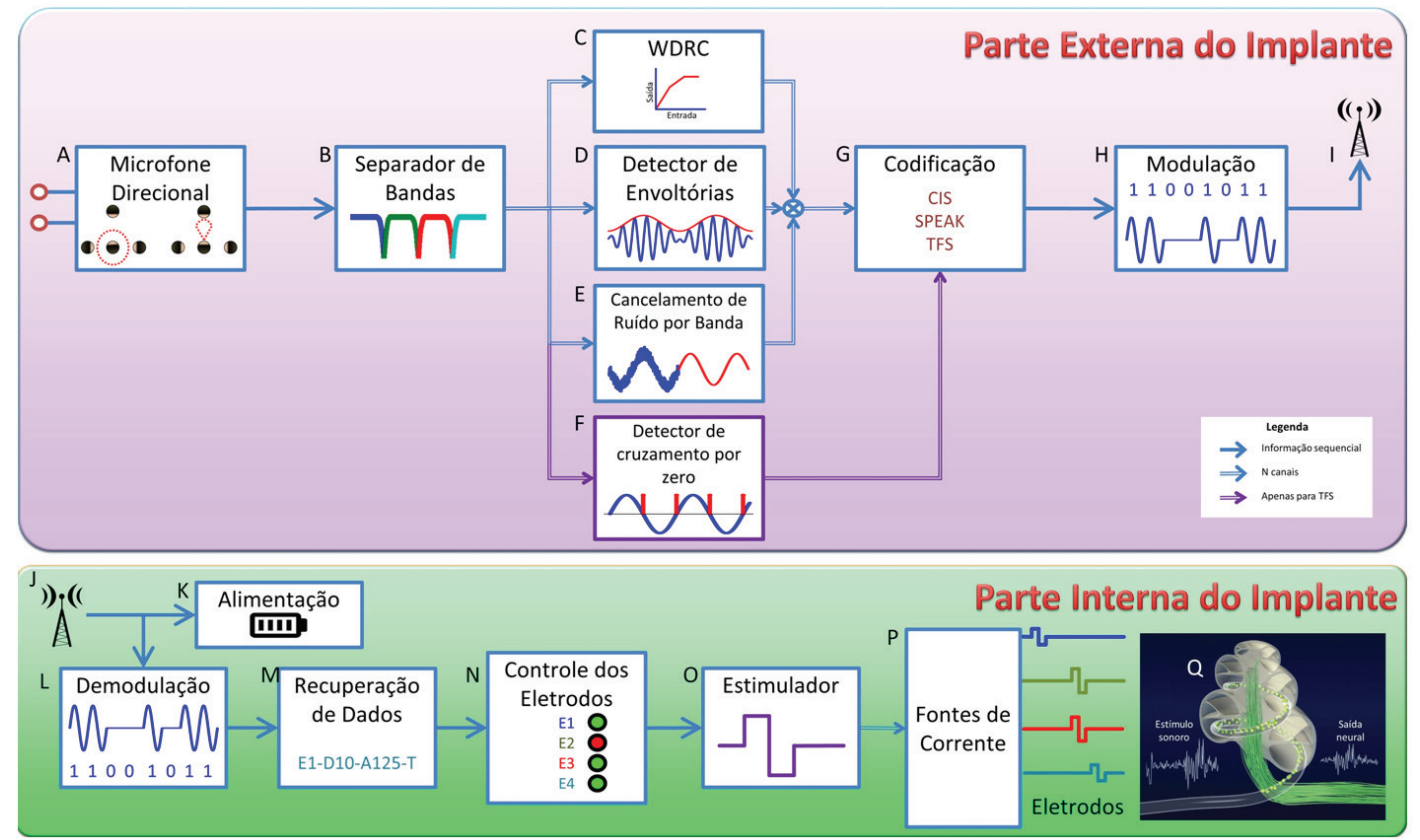

Figura 5. Diagrama de blocos de um implante coclear. O detector de cruzamento por zero não é utilizado em todas as técnicas de estimulação, sendo desnecessário em estratégias como CIS e SPEAK. A ilustração da cóclea (Q) foi adaptada de Wallace et al. (2009).

Figure 5. Block diagram of a cochlear implant. The zero crossing detector is not present in all stimulation techniques, being unnecessary on strategies as CIS and SPEAK. The cochlea illustration was adapted from Wallace et al. (2009).

diferença de direção entre o sinal desejado e o sinal de ruído (Luo et al., 2002) de forma adaptativa para rastrear fontes de ruído em movimento ou variáveis (controle de diretividade). O som vindo da direção frontal do usuário é favorecido, e o proveniente da fonte de ruído é atenuado.

Outro estágio de redução de ruído (Figura 5E) baseia-se nas propriedades típicas de sinais de ruído e de voz. Assume-se que o ruído ambiente tem variação lenta, enquanto que a fala varia rapidamente (Thiemann, 2001). Com base nisso, pelo cálculo de duas médias móveis, os sinais de fala e de ruído podem ser separados. Com estes valores, estima-se a relação sinal-ruído (Signal to Noise Ratio - SNR) e reduz-se o ganho das faixas de frequências (bandas) com menor SNR (Kam et al., 2012).

\section{Processamento do sinal e codificação}

O primeiro estágio do processamento do sinal é sua divisão em faixas de frequência, também chamadas de bandas, por um banco de filtros (Figura 5B), e à saída de cada banda é aplicado um detector de envoltórias (Figura 5D). Este algoritmo calcula uma média móvel da amplitude do sinal para extrair a energia em cada banda, podendo ser realizado por retificação seguida de filtragem passa-baixas ou pela Transformada de Hilbert (Lorens et al., 2010; Zeng et al., 2008).
As envoltórias das bandas de frequência do sinal de áudio contêm as componentes mais significativas para o reconhecimento da fala (Moore, 2008), e são, geralmente, suficientes para inteligibilidade na ausência de ruído (Xu e Pfingst, 2008). Variações mais rápidas compõem a estrutura temporal fina (Temporal Fine Structure - TFS), importante para discriminação de tons e reconhecimento da fala na presença de ruído (Moore, 2008).

Os valores de amplitude das envoltórias são utilizados para modular proporcionalmente pulsos de corrente elétrica (Figura 5P), de forma que, quanto maior a amplitude do sinal de uma banda de frequência, maior deve ser a corrente elétrica imposta ao(s) eletrodo(s) correspondente(s) (Carlson et al., 2012; Wilson et al., 1993).

Em se tratando de estimulação neural, é imprescindível manter o equilíbrio eletroquímico do meio, ou seja, toda carga elétrica que for entregue ao nervo deve ser reabsorvida pelo dispositivo. A forma de onda básica utilizada em implantes cocleares é uma onda bifásica formada por um pulso de corrente numa direção seguido de outro na mesma direção com sentido contrário (Wilson et al., 1993), conforme observado na Figura 5O. Desta forma, a variação de carga é nula após a estimulação, visto que o produto 
entre a amplitude e a duração de cada fase são iguais em módulo e tem sinais contrários (Miller et al., 2001).

\section{Estratégias de estimulação}

Existem diversas maneiras de se codificar o sinal na forma de pulsos para neuro-estimulação. Uma das técnicas mais influentes é a amostragem contínua alternada (Continuous Interleaved Sampling - CIS), na qual pulsos bifásicos proporcionais às envoltórias das bandas são entregues aos eletrodos a uma taxa contínua. A taxa de pulsos é tipicamente maior que 800 pulsos por segundo (pps) por eletrodo (Wilson et al., 1993). A hipótese de que acréscimo na taxa de pulsos pudesse melhorar o entendimento devido à maior definição temporal não se mostrou verdadeira (Loizou, 1998; Zeng et al., 2008). Isso se deve ao fato de que, após receberem um estímulo, as fibras nervosas precisam de um intervalo para se repolarizarem, chamado de período refratário (Clark et al., 1977). Esta técnica, ou uma de suas variações, está presente em todos os modelos atuais de implantes cocleares. Uma destas variações, por exemplo, é chamada de amostrador pulsátil pareado (Paired Pulsatile Sampler-PPS), que aciona dois eletrodos não adjacentes simultaneamente, conseguindo, assim, altas taxas de estimulação com interação mínima entre eletrodos (Zeng, 2004).

Outra maneira de gerar os estímulos é através da seleção de picos espectrais. Neste enfoque, todas as envoltórias são amostradas, porém, apenas os canais de maior amplitude são selecionados. Com isso, diminui-se a densidade de estímulos e a sobreposição de correntes (Wilson e Dorman, 2008). Na técnica $N$-of- $M$, o número de canais selecionados é fixo, enquanto que nas técnicas ACE (Skinner et al., 2002) e SPEAK (Skinner et al., 1994; Somek et al., 2006) o número de canais é adaptativo, variando de acordo com o nível e a composição espectral do sinal de entrada. Na técnica SPEAK, a taxa de pulsos por eletrodo varia tipicamente entre 180 e 300 pps, enquanto que na técnica $\mathrm{ACE}$, varia entre 250 e 2400 pps (Carlson et al., 2012).

As técnicas descritas anteriormente (CIS, $N$-of- $M$, ACE e SPEAK) utilizam apenas os valores das envoltórias para codificar o áudio. Nos últimos anos, a atenção dos pesquisadores tem se voltado para a representação da informação descartada pela detecção de envoltórias: a estrutura temporal fina (Temporal Fine Structure) (Vermeire et al., 2010). Essas variações mais rápidas no sinal são responsáveis pela discriminação de tons (melodias) e pela localização espacial da fonte sonora (Smith et al., 2002). Para codificar a estrutura fina, pode-se emitir pacotes de pulsos nos momentos em que a onda de uma banda de frequência cruza a linha de amplitude zero (zero-crossing detection). Outra maneira consiste em se variar a taxa de pulsos de acordo com as variações da estrutura fina (Vermeire et al., 2010).

A codificação deve ainda determinar o modo de geração de corrente nos eletrodos. O mais utilizado é o modo monopolar (Kwon e van den Honert, 2006), no qual a corrente sai de um eletrodo intracoclear e retorna por um eletrodo de referência extracoclear. Devido à distância dos eletrodos ativos em relação ao de referência extracoclear e à condutividade elétrica relativamente alta da perilinfa (líquido da cóclea), ocorre uma dispersão significativa da corrente elétrica, o que reduz a definição espectral disponível. Este fenômeno é ilustrado na Figura 6, e consiste em um dos maiores desafios para o aprimoramento dos implantes cocleares atuais.

O modo bipolar foi projetado para reduzir a dispersão de corrente e, consequentemente, a interação entre eletrodos. Estimulando-se a região entre 2 eletrodos adjacentes, aumenta-se a focalização do estímulo. No entanto, com as tecnologias atuais, o reconhecimento da fala é relatado como igual ou melhor em modo monopolar, pelo qual muitos pacientes expressam preferência. Além disso, na estimulação

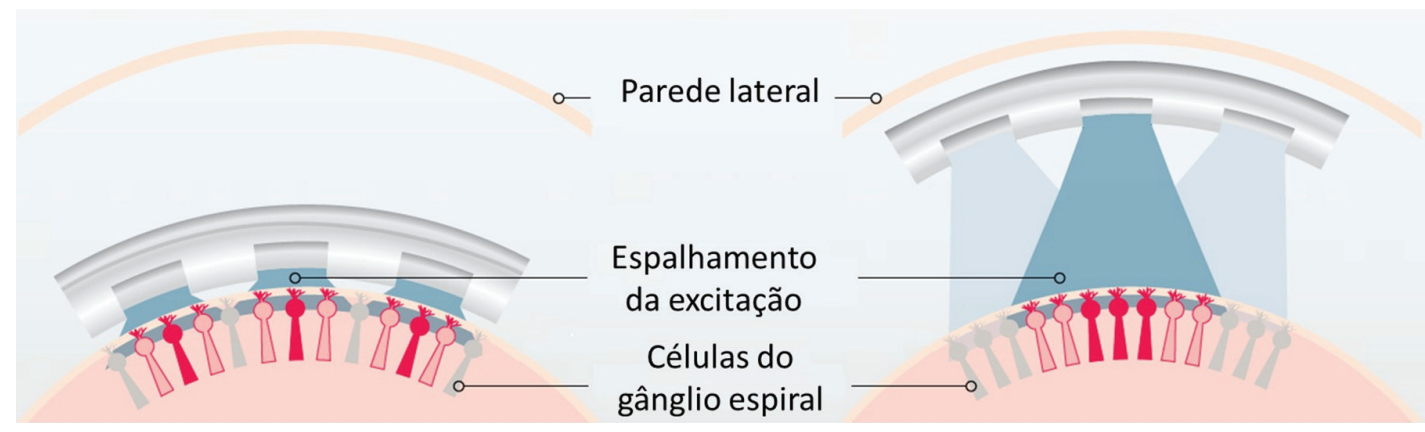

Figura 6. Modo de estimulação monopolar e dispersão de corrente variando com a posição do conjunto de eletrodos. Adaptado de Cochlear Ltd. (2011).

Figure 6. Monopole stimulation and current spread varying with the positioning of the electrode array. Adapted from Cochlear Ltd. (2011). 
bipolar, é necessário aplicar correntes maiores do que as do modo monopolar para produzir os mesmos limiares de audição. Devido a seu melhor desempenho, rendimento e preferência expressa por muitos pacientes, o modo monopolar é o mais empregado clinicamente (Kwon e van den Honert, 2006).

Pessoas com audição normal tem uma faixa dinâmica de cerca de 100 a 120 dB (diferença entre o limiar de audição e o limiar da dor), e a fala geralmente ocupa uma faixa dinâmica de $50 \mathrm{~dB}$ (Zeng et al., 2002). Para estimulação elétrica, essa faixa dinâmica é menor, de 3 a $24 \mathrm{~dB}$ (Eddington et al., 2001). Além disso, a faixa dinâmica varia de acordo com a frequência. Para condicionar o sinal útil entre o limiar de percepção e o nível de audição confortável, é necessário aplicar um ganho não-linear a cada banda de acordo com a necessidade do paciente (Zeng et al., 2008). Esse procedimento é chamado de compressão do sinal e, em resumo, significa a amplificação de sons de baixa intensidade e a atenuação de sons de alta intensidade.

Outra característica da perda auditiva neurossensorial é que a mesma ocorre com diferentes níveis de acordo com a faixa de frequência. Assim, de forma a otimizar o processo de compressão, o mesmo é aplicado ao sinal separado em bandas de frequência, de modo a ser possível ajustar os seus parâmetros para cada uma das bandas definidas.

\section{Comunicação entre unidade externa e estimulador implantado}

O sistema de comunicação e/ou transmissão de energia entre a cápsula externa e o sistema implantado deve equilibrar três principais exigências: alta taxa de transferência de dados, alta eficiência de transmissão de energia e tolerância ao desacoplamento (Wang et al., 2008).

A comunicação entre o dispositivo externo e o implantado é feita por acoplamento indutivo entre duas antenas de radiofrequência. $\mathrm{O}$ sinal de dados controla um oscilador de potência alimentado por baterias e é transmitido através da pele, num arranjo conhecido como transformador transcutâneo (Matsuki et al., 1996). A antena externa consiste tipicamente de uma bobina circular com aproximadamente $30 \mathrm{~mm}$ de diâmetro (Patrick et al., 2006), e a interna pode ter formato circular ou espiral, com diâmetro semelhante. No centro de cada antena há um ímã para fazer a sustentação mecânica e manter o alinhamento das antenas.

A alimentação dos circuitos internos é feita por recuperação da energia (power harvesting) de radiofrequência captada pela antena interna por meio de retificação e armazenamento desta energia em capacitores. Atualmente, a conexão por radiofrequência tem eficiência de cerca de $40 \%$, transmitindo $20-40 \mathrm{mV}$ para a unidade interna através da pele com espessura de 4 a 10 mm (Zeng et al., 2008).

\section{Estimulação}

A estimulação elétrica é feita no interior da cóclea através de um feixe de eletrodos inseridos na escala (ou rampa) timpânica, porção da cóclea localizada abaixo da membrana basilar, conforme Figura 7. Devido à imprecisão no posicionamento manual durante o procedimento cirúrgico, a posição dos eletrodos pode não corresponder exatamente à faixa de frequência pré-definida de cada canal. Mesmo neste caso, a ordem dos eletrodos mantém um padrão crescente de frequência a partir do ápice da cóclea em direção à base da mesma. Porém, a imprecisão no
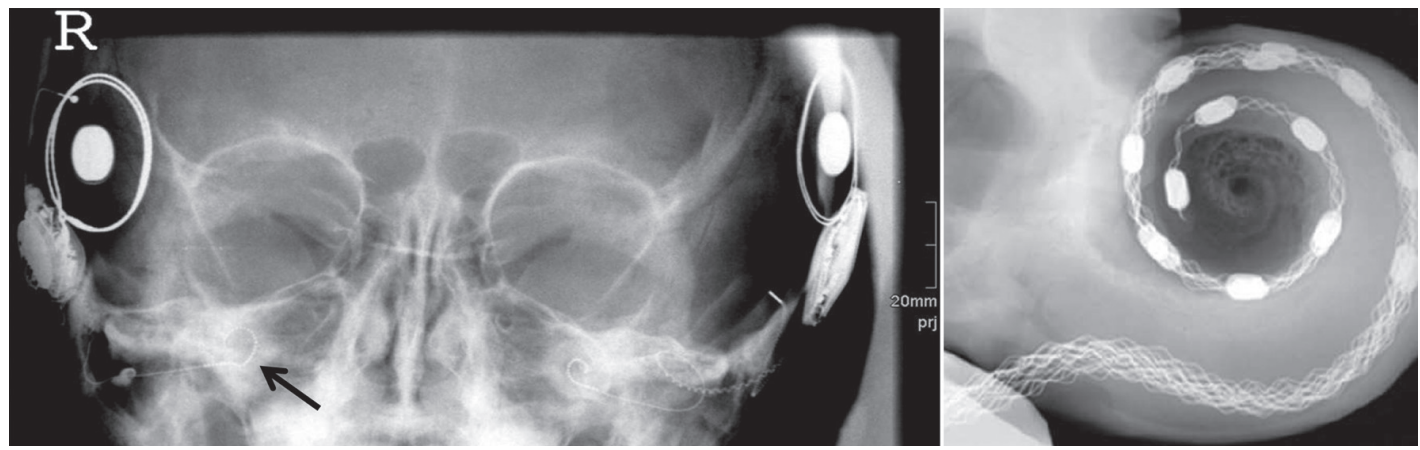

Figura 7. Radiografia de paciente implantado bilateralmente, destacando os eletrodos (Aschendorff, 2011) e ampliação em um feixe de eletrodos dentro da cóclea (Roland Jr., 2005).

Figure 7. Bilateral implant radiography, emphasizing the electrodes (Aschendorff, 2011) and zoom in an electrode array in the cochlea (Roland Jr., 2005) 
posicionamento pode fazer com que todo o sinal fique deslocado na frequência, exigindo do cérebro alguns meses para se adaptar ao novo tipo de informação e (re)aprender a ouvir (Başkent e Shannon, 2005). Em geral, usuários conseguem se adaptar a deslocamentos de frequências de até 30\% (McKay e Henshall, 2002). Este período de adaptação pode ser longo mesmo com as técnicas atuais, e alguns pacientes continuam a evoluir seu entendimento até alguns anos depois da ativação do implante (Beadle et al., 2005).

Em geral, a estimulação elétrica deve ser feita por fontes de corrente, e não de tensão, devido à variações na impedância elétrica entre eletrodos. A resposta neural se dá pelo fluxo de cargas (corrente elétrica), de modo que a diferença de potencial tem um efeito secundário. Além disso, apenas por meio da definição da intensidade da corrente é possível obter controle da quantidade de carga elétrica entregue à cóclea, o que é crucial para a manutenção do equilíbrio eletroquímico do meio e evitar corrosão dos eletrodos, que pode gerar gases, íons tóxicos e alterações de $\mathrm{pH}$ (Shepherd et al., 1999; Zeng et al., 2008).

A inserção do conjunto na rampa timpânica deve causar o menor dano possível às estruturas internas da cóclea para não prejudicar a audição residual do paciente (Carlson et al., 2012; Ilberg et al., 2011). No caso de ossificação da cóclea, fica dificultada a inserção dos eletrodos até a profundidade necessária para estimular regiões relativas a sons de baixa frequência. Para esta situação, pode-se utilizar dois feixes de eletrodos, um dos quais entra pela região basal da cóclea, enquanto que o outro entra pela segunda volta da cóclea, mais próxima da região apical (Carlson et al., 2012).

Uma ferramenta útil para visualização dos efeitos dos parâmetros de estimulação elétrica são os chamados eletrodogramas: gráficos análogos aos espectrogramas que mostram informação relativa à estimulação elétrica como amplitude e número do eletrodo em função do tempo (Zeng et al., 2008). Um exemplo de espectrograma é mostrado na Figura 8A, no qual a amplitude do áudio é representada em cores em função do tempo e da frequência, enquanto que o eletrodograma é mostrado na Figura 8B. Uma visualização mais detalhada do eletrodograma é também mostrada na Figura 8B, onde se pode perceber que o eletrodograma é na verdade composto por um gráfico de barras para cada eletrodo representando a amplitude dos pulsos. Na mesma figura, pode-se observar que os eletrodos não são acionados de forma simultânea.

\section{Telemetria}

Para ajustar e monitorar os estímulos elétricos, é necessário um sistema de sensoriamento que faça medições das propriedades e respostas do meio biológico, entre as quais, os estados dos eletrodos, a impedância entre os mesmos e o potencial de ação em resposta à estimulação (electrically evoked compound action potential - ECAP) (Hochmair et al., 2006). O monitoramento da tensão permite analisar a dispersão da corrente e determinar a região efetivamente estimulada, o que é útil no estudo e desenvolvimento de técnicas de focalização de corrente (Landsberger e Srinivasan, 2009). O ECAP é utilizado para se definir os parâmetros de estimulação específicos para cada eletrodo de cada paciente, quando estes últimos são incapazes de sinalizar o funcionamento e desempenho do implante (crianças, por exemplo) (Zwolan e Griffin, 2005). No entanto, por haver pouca correlação entre a curva de sensibilidade à audição e o ECAP (Potts et al., 2007), devido à saturação deste último,
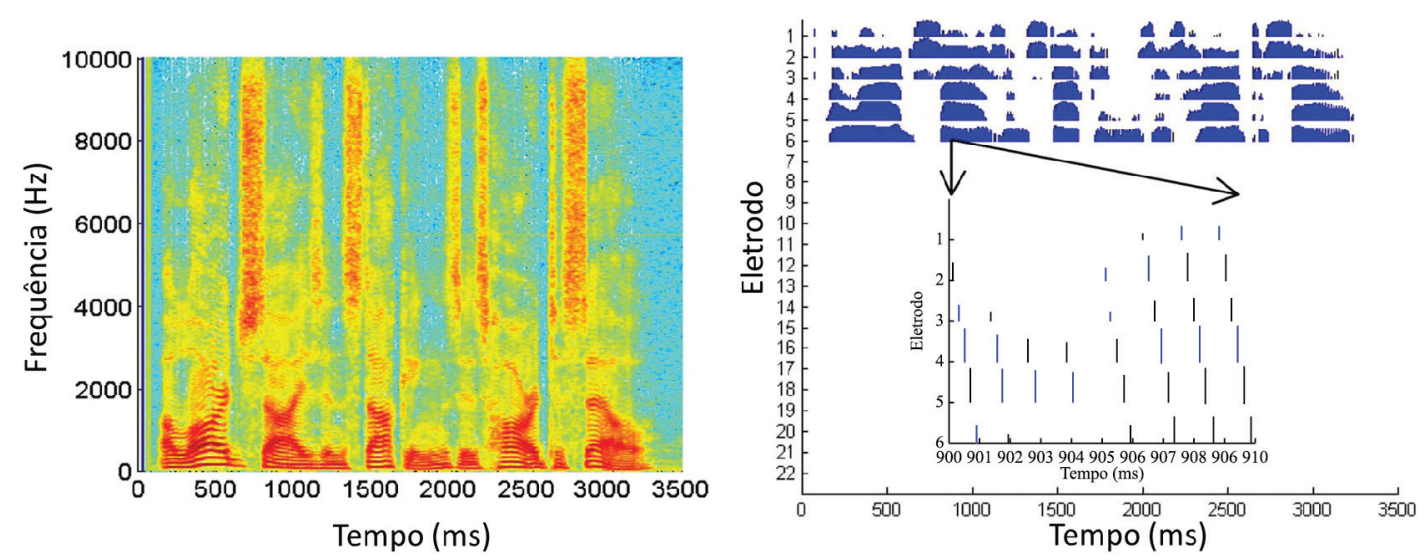

Figura 8. Exemplos de espectrograma e eletrodograma. Adaptado de Zeng et al. (2008).

Figure 8. Spectrogram and electrodogram examples. Adapted from Zeng et al. (2008). 
novos ajustes devem ser feitos através de interação com o paciente, assim que o mesmo for capaz de demonstrar respostas. Quando o comportamento do ECAP for mais bem entendido, talvez seja possível a aplicação de um controle realimentado do estimulador (Botros, 2010; Miller et al., 2008).

\section{Estimulação eletroacústica}

Atualmente, existem modelos híbridos de implantes cocleares dotados de um alto-falante que envia informação acústica ao canal auditivo, enquanto que o sistema implantado entrega ao nervo auditivo somente informação correspondente à região espectral na qual a perda auditiva é muito grande para ser corrigida com a amplificação convencional. Neste caso, o processador de áudio deve desempenhar tanto as funções de geração de código de pulsos quanto as etapas presentes em próteses auditivas convencionais, como síntese de áudio e cancelamento de realimentação, além dos blocos de redução de ruído, presentes em todos os tipos de próteses auditivas. A estimulação eletroacústica possibilita que pacientes sejam beneficiados tanto pela audição via estimulação elétrica quanto pela audição natural remanescente, que lhe garante melhor qualidade (Ilberg et al., 2011). Percepção musical (Kong et al., 2005) e reconhecimento de fala na presença de ruído (Kiefer et al., 2005) são relatados como melhores em pacientes com estimulação eletroacústica do que com apenas elétrica.

\section{Fabricantes}

Atualmente, seis fabricantes de ICs estão presentes no mercado internacional: Cochlear Limited, Advanced Bionics, Med-El, Neurolec, IES e Nurotron. Destes, apenas os 4 primeiros são homologados pela Agência Nacional de Vigilância Sanitária para aplicação clínica no Brasil (2013); sendo que os 3 primeiros detêm a maior parcela do mercado mundial de ICs (Zeng et al., 2008). Em 2010, a Cochlear Limited representava mais de $60 \%$ do mercado mundial (GlobalData, 2012). Em 2012, a Med-El obteve aprovação pelo FDA para um novo modelo denominado Rondo $^{\mathrm{TM}}$, sendo este o primeiro a unir todos os componentes externos em uma só cápsula. Nesse caso, microfone, processador de áudio, baterias e antena são embutidos em uma única peça sustentada por ímãs, eliminando a necessidade do gancho utilizado para prender o aparelho ao pavilhão auditivo e do cabo que conecta o aparelho à antena (MED-EL, 2012a).

\section{Implantes de orelha média}

Pessoas que sofrem de perda auditiva condutiva, neurossensorial ou mista de grau leve a severo, e que não se adequam a aparelhos auditivos tradicionais, podem ser candidatas à utilização de implantes de orelha média (IOM) (Lalwani e Pfister, 2012). Estes são dispositivos implantáveis total ou parcialmente que, diferentemente dos ICs, atuam aplicando vibração mecânica diretamente aos ossículos da orelha média. Através da utilização das estruturas do próprio sistema auditivo, pode-se proporcionar ao paciente uma sensação auditiva mais natural e com melhor qualidade (Haynes et al., 2009) do que aparelhos auditivos convencionais. Além disso, no caso de dispositivos totalmente implantáveis, evita-se parte dos problemas associados aos aparelhos auditivos convencionais, como a limitação de práticas esportivas e o estigma associado a pessoas com perda auditiva. Apesar de relativamente recentes, já existem diferentes modelos de IOM atualmente sendo implantados. O modelo mais comercializado de IOM é o Vibrant Soundbridge ${ }^{\circledR}$ (Med-El), dispositivo parcialmente implantável no qual o som é captado por um microfone, processado na cápsula externa e enviado por radiofrequência para o receptor implantado, o qual é responsável por transmitir um sinal para um dispositivo eletrodinâmico acoplado aos ossículos, provocando sua vibração e gerando uma sensação auditiva (Kasic e Fredrickson, 2001; Wolf-Magele et al., 2011). Já o modelo CarinaTM (Otologics) representa um IOM totalmente implantável, e utiliza um microfone subcutâneo para captar o som ambiente, o qual é processado e enviado ao dispositivo eletrodinâmico acoplado aos ossículos (Bruschini et al., 2010). Outro modelo de IOM totalmente implantável é o Esteem ${ }^{\circledR}$ (Envoy), no qual a captação do sinal acústico dá-se por um sensor piezoelétrico conectado diretamente à bigorna, e a estimulação é feita por um atuador também piezoelétrico ligado ao estribo. Neste caso, o papel do microfone é desempenhado pelo conjunto formado pela membrana timpânica e o transdutor piezoelétrico, o que proporciona um sinal acústico de maior qualidade devido às propriedades naturais da orelha externa e média (Barbara et al., 2009; Chen et al., 2004). No caso do Esteem, o sistema é alimentado por baterias cuja reposição deve ser feita a cada 5 a 9 anos, dependendo do modelo e variando de um paciente para outro, através de cirurgia ambulatorial (Green, 2011).

\section{Perspectivas}

Embora usuários de implante coclear consigam bom desempenho de reconhecimento de voz na ausência de ruído, ainda não se atingiu eficiência similar em ambientes ruidosos ou com relação à apreciação musical. Com as técnicas atuais, raramente há ganho significativo de entendimento vocal com um número de canais acima de 8 , principalmente devido à interação entre os eletrodos. As estratégias 
de estimulação tem sido um dos alvos de pesquisa, tendo por objetivo aumentar o número de canais virtuais disponíveis (Vondrasek et al., 2008), sendo que alguns resultados destas pesquisa já estão sendo utilizados clinicamente (Firszt et al., 2009). Busca-se, ainda, redução da interferência entre os estímulos através de focalização da corrente elétrica na cóclea (Landsberger e Srinivasan, 2009).

Uma alternativa ainda em investigação é a estimulação ótica da cóclea. Foi demonstrado em animais que pulsos de laser são capazes de evocar potenciais de ação no nervo auditivo. Uma explicação sugerida para este fenômeno é que a energia ótica provoque aquecimento dos tecidos, induzindo fluxo de íons nas células atingidas (Richter et al., 2008; Wells et al., 2006). Somente as células que se encontram diretamente no caminho ótico são estimuladas. Com isso, há possibilidade de aumento na resolução espectral em comparação com a estimulação por corrente elétrica (Izzo et al., 2007). No entanto, ainda é necessário comprovar que a aplicação crônica da estimulação por radiação ótica é segura (Richter et al., 2008), bem como determinar os parâmetros adequados do laser a ser empregado (Wenzel et al., 2009).

Outra área de desenvolvimento busca melhorar a qualidade da informação entregue através da representação da estrutura temporal fina. Os estímulos das técnicas tradicionais baseiam-se somente nas envoltórias das bandas de frequência, descartando completamente a informação contida na fase e nas variações rápidas do sinal. A recuperação dessa informação pode trazer aprimoramento no desempenho em reconhecimento da fala em ambientes ruidosos e na apreciação musical (Chen e Zhang, 2011; Schatzer et al., 2010; Sawigun et al., 2010; Vermeire et al., 2010).

A implantação bilateral é outro ponto importante de estudo com potencial de aprimoramento para os ICs. Em situações nas quais fala e ruído provém de direções diferentes, o efeito da sombra da cabeça permite que os pacientes usem a orelha com a melhor relação sinal-ruído. Quando fala e ruído originam-se da mesma direção, alguns pacientes percebem aprimoramento devido à redundância binaural em comparação com uso da melhor orelha unicamente. O desempenho varia entre os pacientes, sugerindo que nem todos os implantados são capazes de usar a informação adicional de um segundo IC (Patrick et al., 2006). Possivelmente, o aprimoramento de estratégias de codificação considerando a bilateralidade seja capaz de melhorar ainda mais os resultados (Hoesel, 2004). Ainda assim, o Fórum de Implante Coclear Bilateral Europeu de 2012 anunciou consenso de que o melhor tratamento disponível atualmente é a implantação bilateral precoce (Ramsden et al., 2012).
Atualmente, o SUS fornece apenas implantes unilaterais. O principal empecilho para a bilateralidade é o custo do IC, e questionamentos quanto à relação custo-benefício do segundo implante (Summerfield e Barton, 2003). Com o objetivo de reduzir os custos, a Neurolec S.A. desenvolveu o implante Digisonic ${ }^{\circledR}$ SP Binaural. Este dispositivo tem custo médio cerca de $30 \%$ acima de um IC unilateral e traz os mesmos benefícios do uso de dois implantes independentes, pois possui um processador de fala que analisa separadamente os sinais provenientes de dois microfones (um localizado em cada orelha) e os envia para os eletrodos implantados nas duas cócleas. A desvantagem deste modelo é a presença de apenas 12 eletrodos por feixe (Carvalho et al., 2013).

A necessidade de uma unidade externa é frequentemente motivo de desconforto e limitação para os usuários. A sensibilidade da cápsula a impactos e à umidade representam um risco constante e impossibilitam o uso em ambientes hostis e durante o sono e banho (Ko et al., 2009). Para contornar estas barreiras, uma possível solução é o desenvolvimento de um implante coclear invisível, ou seja, totalmente implantável. As principais dificuldades relacionadas a sistemas totalmente implantáveis são a captação do sinal e a durabilidade da bateria (Briggs et al., 2008; Carlson et al., 2012; Green, 2011). Microacelerômetros tem sido propostos como nova forma de captação de sinal (Ko et al., 2009; Young et al., 2007). Devido a seu tamanho e massa reduzidos, espera-se que os micro-acelerômetros causem pouca interferência no funcionamento natural dos ossículos da orelha média, preservando a audição residual do paciente. O ponto de captação de sinal proposto para acelerômetros é o umbo, localizado na região central interna da membrana timpânica, por ser o local com maior amplitude de vibração (Young et al., 2007). Assim, elimina-se a distorção gerada por microfone e a necessidade de um sensor externo ao corpo. A empresa Cochlear Ltd. está em fase de avaliação de um implante invisível chamado TIKI, cuja bateria recarregável tem vida útil estimada em 6 anos. O protótipo utiliza um microfone subcutâneo no corpo do dispositivo implantado. Entretanto, testes iniciais mostram que este sensor sofre com perda de sensibilidade ao sinal externo e com a interferência de ruídos naturais do corpo (Briggs et al., 2008). Sugere-se que, unindo as tecnologias de captação de sinal dos implantes de orelha média e a forma de estimulação dos implantes cocleares, seja possível desenvolver um dispositivo invisível de melhor qualidade (Carlson et al., 2012).

Com vistas no futuro, o aumento contínuo da demanda brasileira e dos recursos empregados na importação de ICs apontam à crescente dependência nacional de produtos estrangeiros. $\mathrm{O}$ desenvolvimento de produção brasileira surge como uma alternativa 
para a substituição de importações e a regionalização do suporte ao produto. Com isso proporciona-se o desenvolvimento tecnológico local além de tornar mais fácil o acesso da população à assistência e à manutenção dos produtos.

\section{Conclusão}

Uma revisão bibliográfica sobre os principais aspectos socioeconômicos e tecnológicos de implantes cocleares (IC) foi apresentada neste trabalho. Inicialmente, buscou-se descrever o sistema auditivo e os mecanismos da perda auditiva de forma a destacar as aplicações dos ICs. Embora apenas uma parcela dos deficientes auditivos possa se beneficiar de um IC, mostrou-se que o número daqueles que se enquadram nos requisitos para receber um IC é significativo. Pode-se observar que os impactos da perda auditiva sobre a qualidade de vida do deficiente são relevantes, assim como os impactos econômicos da perda de produtividade e custos com educação especial, os quais podem chegar até a US\$ 1 milhão por deficiente. Nesse sentido, a literatura comprova a eficiência do IC em minimizar os efeitos da perda auditiva. Estudos recentes destacam ainda a importância da implantação precoce em crianças de forma a garantir o pleno desenvolvimento do sistema auditivo central, maximizando os ganhos decorrentes do IC. Apesar dos altos impactos da perda auditiva e dos ganhos decorrentes do IC, viu-se que, no caso da realidade brasileira, apenas um número restrito das pessoas que podem receber um IC é realmente atendido. Nesse sentido, o alto custo do implante coclear devido à inexistência de uma indústria nacional é o principal fator limitante para um maior número de implantações. Ainda com relação à situação no Brasil, o fato de o SUS não fornecer manutenção dos ICs constitui um sério problema para usuários de baixa renda, uma vez que defeitos ou falta de baterias podem fazer com que o implantado fique impossibilitado de utilizar o IC. Com isso, o potencial de benefício socioeconômico do investimento é perdido, aumentando o ônus social e trazendo frustração a pacientes e familiares. A literatura carece de estudos que avaliem a eficácia do protocolo de atendimento ao implantado e que possam servir como base para reformas nas portarias de seleção de candidatos, bem como nas políticas públicas de acompanhamento pós-operatório.

No âmbito tecnológico, mostrou-se que o aprimoramento dos ICs representa um desafio eminentemente multidisciplinar, envolvendo profissionais de áreas como microeletrônica, neurociência, vibração, acústica, psicoacústica, radiofrequência, etc. Como maiores desafios identificados na literatura para os ICs na atualidade tem-se: (i) obter uma melhor definição do sinal elétrico aplicado ao meio líquido da cóclea, o que permitiria focalizar a excitação elétrica em uma região específica da membrana basilar e assim obter uma maior resolução na frequência; (ii) a incorporação da estrutura fina do sinal e sua fase nas informações repassadas através da excitação elétrica da cóclea, o que abre a possibilidade de um ganho de qualidade no entendimento da fala em ambientes ruidosos e um aprimoramento da percepção musical; (iii) aprimoramento dos sistemas bilaterais, cuja eficácia ainda é questionada em alguns casos, mas cujo potencial é grande principalmente no caso de ambientes ruidosos, e (iv) desenvolver implantes cocleares totalmente implantáveis, ou seja, invisíveis, o que permitira a utilização do IC em tempo integral e reduziria os problemas associados à discriminação dos deficientes auditivos, principalmente no caso de crianças e adolescentes. No caso do item (iv), as principais barreiras a serem transpostas para o desenvolvimento do IC totalmente implantável residem em obter baterias com vida suficientemente longa e o desenvolvimento de transdutores (acelerômetros e/ou microfones) que possam ser implantados e permitam captar os sinais do campo acústico externo com qualidade suficiente. Finalmente, deve-se destacar a importância do desenvolvimento de tecnologia nacional na área de implantes cocleares, de forma a permitir o surgimento futuro de uma indústria local, além de assegurar o domínio de tecnologia que deve se tornar cada vez mais importante com as perspectivas de surgimento de novos dispositivos biomédicos cujo funcionamento ocorre através do acoplamento direto com o sistema nervoso central.

\section{Agradecimentos}

Os autores gostariam de agradecer à Universidade Federal de Santa Catarina (UFSC) e à empresa WaveTech Soluções Tecnológicas pelo suportes financeiro e tecnológico fornecidos durante o trabalho.

\section{Referências}

Agência Nacional de Saúde Suplementar - ANS. Resolução normativa $n^{\circ} 211$, de 11 de janeiro de 2010 [Internet]. Rio de Janeiro: ANS; 2010. [acesso em 2013 jan 02]. Disponível em: http://www.ans.gov.br/images/stories/Legislacao/ rolprocedimentos/anexoii_rn262_integra_rn211.pdf.

Agência Nacional de Vigilância Sanitária-Anvisa. [Internet]. Brasília: ANVISA; 2013. [acesso em 2013 jan 02]. Disponível em: http://s.anvisa.gov.br/wps/s/r/G.

Aschendorff A. Imaging in cochlear implant patients. GMS Current Topics in Otorhinolaryngology, Head and Neck Surgery. 2011; 10.

Associação dos Deficientes Auditivos, Pais, Amigos e Usuários de Implante Coclear - ADAP. [Internet]. Bauru: 
ADAP; 2013. [acesso em 2013 ago 05]. Disponível em: http://www.adap.org.br.

Barbara M, Manni V, Monini S. Totally implantable middle ear device for rehabilitation of sensorineural hearing loss: preliminary experience with the esteem ${ }^{\circledR}$, envoy. Acta Oto-Laryngologica. 2009; 129(4):429-32. http://dx.doi. org $/ 10.1080 / 00016480802593505$

Başkent D, Shannon R. Interactions between cochlear implant electrode insertion depth and frequencyplace mapping. The Journal of the Acoustical Society of America. 2005; 117(3 Pt 1):1405-16. http://dx.doi. org/10.1121/1.1856273

Beadle E, McKinley D, Nikolopoulos T, Brough J, O'Donoghue G, Archbold S. Long-term functional outcomes and academic-occupational status in implanted children after 10 to 14 years of cochlear implant use. Otology \& Neurotology. 2005; 26(6):1152-60. http://dx.doi. org/10.1097/01.mao.0000180483.16619.8f

Berne RM, Koeppen BM, Stanton BA. Berne \& Levy Physiology. 6th ed. Philadelphia: Mosby, Elsevier; 2010.

Bond M, Mealing S, Anderson R, Elston J, Weiner G, Taylor R, Hoyle M, Liu Z, Price A, Stein K. The effectiveness and cost-effectiveness of cochlear implants for severe to profound deafness in children and adults: a systematic review and economic model. Health Technology Assessment. 2009; 13(44):1-330. http://dx.doi.org/10.3310/ hta 13440

Botros AM. The application of machine intelligence to cochlear implant fitting and the analysis of the auditory nerve response [tese]. Sydney: The University of New South Wales; 2010.

Brasil. Ministério da Saúde. Portaria GM/MS nº 1.279, de 20 de outubro de 1999. [Internet]. Diário Oficial da República Federativa do Brasil, Brasília; out. 1999. Disponível em: http://bvsms.saude.gov.br/bvs/saudelegis/gm/1999/ prt1278_20_10_1999.html.

Brasil. Ministério da Saúde. Departamento de Informática do Sistema Único de Saúde (DATASUS). Informações da saúde. Brasília: Ministério da Saúde; 2013a.

Brasil. Ministério da Saúde. Departamento de Informática do Sistema Único de Saúde (DATASUS). Sistema de Gerenciamento da Tabela de Procedimentos, Medicamentos e OPM do SUS. Brasília: Ministério da Saúde; 2013b.

Briggs R, Eder H, Seligman P, Cowan R, Plant K, Dalton J, Money D, Patrick J. Initial clinical experience with a totally implantable cochlear implant research device. Otology \& Neurotology. 2008; 29(2):114-9. http://dx.doi.org/10.1097/ MAO.0b013e31814b242f

Bruschini L, Forli F, Passetti S, Bruschini P, Berrettini S. Fully implantable otologics met carina ${ }^{\mathrm{TM}}$ device for the treatment of sensorineural and mixed hearing loss: Audio-otological results. Acta oto-laryngologica. 2010; 130(10):1147-53. http://dx.doi.org/10.3109/00016481003671244

Budenz C, Cosetti M, Coelho D, Birenbaum B, Babb J, Waltzman S, Roehm P. The effects of cochlear implantation on speech perception in older adults. Journal of the American Geriatrics Society. 2011; 59(3):446-53. http://dx.doi. org/10.1111/j.1532-5415.2010.03310.x
Carlson M, Driscoll C, Gifford R, McMenomey S. Cochlear implantation: current and future device options. Otolaryngologic Clinics of North America. 2012; 45(1):221-48. http://dx.doi.org/10.1016/j. otc.2011.09.002

Carter R, Hailey D. Economic evaluation of the cochlear implant. International Journal of Technology Assessment in Health Care. 1999; 15:520-30.

Carvalho GM, Guimarães AC, Macedo ISC, Onuki LCB, Danieli F, Pauna HF, Fernandes FL, Paschoal JR, Bianchini WA, Castilho AM. Digisonic sp ${ }^{\circledR}$ binaural cochlear implant: the coronal tunneled approach. Brazilian journal of Otorhinolaryngology. 2013; 79(3):298-305. http://dx.doi. org/10.5935/1808-8694.20130054

Chen DA, Backous DD, Arriaga MA., Garvin R, Kobylek D, Littman T, Walgren S, Lura D. Phase 1 clinical trial results of the envoy system: a totally implantable middle ear device for sensorineural hearing loss. OtolaryngologyHead and Neck Surgery. 2004; 131(6):904-16. http://dx.doi. org/10.1016/j.otohns.2004.05.027

Chen F, Zhang Y. Zerocrossing-based nonuniform sampling to deliver low-frequency fine structure cue for cochlear implant. Digital Signal Processing. 2011; 21(3):427-32. http://dx.doi.org/10.1016/j.dsp.2010.12.002

Cheng A, Rubin H, Powe N, Mellon N, Francis H, Niparko J. Cost-utility analysis of the cochlear implant in children. The Journal of the American Medical Association. 2000; 284(7):850-6. http://dx.doi.org/10.1001/ jama.284.7.850

Ching T, Dillon H, Byrne D. Speech recognition of hearingimpaired listeners: Predictions from audibility and the limited role of high-frequency amplification. The Journal of the Acoustical Society of America.1998; 103(2):1128-40. http://dx.doi.org/10.1121/1.421224

Clark G, Tong Y, Black R, Forster I, Patrick J, Dewhurst D. A multiple electrode cochlear implant. The Journal of Laryngology \& Otology1977; 91(11):935-45. http://dx.doi. org/10.1017/S0022215100084607

Cochlear Ltd. Nucleus ${ }^{\circledR} \operatorname{cp} 810$ sound processor user guide [Internet]. Sydney: Cochlear Ltd; 2009. [acesso em 2013 nov 30]. Disponivel em: http://www.cochlearamericas.com/ PDFs/CP810UserGuide.pdf.

Cochlear Ltd. The cochlear electrode portfolio [Internet]. Sydney: Cochlear Ltd; 2011. [acesso em 2013 nov 30]. Disponivel em: http://www.cochlear.com/files/assets/ N35048F_ISS1_EN_Electrode portfolio_lr.pdf

Cole E, Flexer C. Children with hearing loss: Developing listening and talking, birth to six. San Diego, CA: Plural Publishing; 2007.

Conselho Federal de Fonoaudiologia, Conselho Regional de Fonoaudiologia. Audiometria tonal, logoaudiometria e medidas de imitância acústica. Brasília: Conselhos Federal e Regionais de Fonoaudiologia; 2009.

Costa S, Cruz OLM, Oliveira JAA. Otorrinolaringologia: princípios e prática. Porto Alegre: Artmed Editora; 2006.

Cruz I, Quittner AL, Marker C, DesJardin JL. Identification of effective strategies to promote language in deaf children with cochlear implants. Child Development. 2013; 84(2):54359. Epub 2012 Set 24 
Davidson L, Geers A, Blamey P, Tobey E, Brenner C. Factors contributing to speech perception scores in long-term pediatric cochlear implant users. Ear and Hearing. 2011; 32(1 Suppl):19S-26S. http://dx.doi. org/10.1097/AUD.0b013e3181ffdb8b

Doyle KJ, Burggraaff B, Fujikawa S, Kim J. Newborn hearing screening by otoacoustic emissions and automated auditory brainstem response. International Journal of Pediatric Otorhinolaryngology. 1997; 41(2):111-9. http:// dx.doi.org/10.1016/S0165-5876(97)00066-9

Eddington DK, Rabinowitz WM, Delhorne LA. Sound processing for cochlear implants. Proceedings IEEE International Conference Acoustics, Speech, and Signal Processing. 2001; 6:3449-52.

Food and Drug Administration - FDA. Medical devices [Internet]. Silver Spring: FDA; 1984. [acesso em 2013 jan 02]. Disponível em: http://www.accessdata.fda.gov/ scripts/cdrh/devicesatfda/index.cfm?db=pma\&id $=2324$.

Fettiplace R, Hackney C. The sensory and motor roles of auditory hair cells. Nature Reviews Neuroscience. 2006; 7(1):19-29. http://dx.doi.org/10.1038/ nrn1828

Firszt J, Holden L, Reeder R, Skinner M. Speech recognition in cochlear implant recipients: comparison of standard hires and hires 120 sound processing. Otology \& Neurotology. 2009; 30(2):146-52. http://dx.doi.org/10.1097/ MAO.0b013e3181924ff8

Geers A, Moog J, Biedenstein J, Brenner C, Hayes H. Spoken language scores of children using cochlear implants compared to hearing age-mates at school entry. Journal of Deaf Studies and Deaf Education. 2009; 14(3):371-85. http://dx.doi.org/10.1093/deafed/enn046

Gilley P, Sharma A, Dorman M. Cortical reorganization in children with cochlear implants. Brain research. 2008; 1239:56-65. http://dx.doi.org/10.1016/j. brainres.2008.08.026

GlobalData. Hearing implants - global pipeline analysis, competitive landscape and market forecasts to 2017. Londres: GlobalData; 2012.

Gontijo LV. A compreensão dos profissionais sobre a portaria $\mathrm{gm} / \mathrm{ms} \mathrm{n}^{\circ}$ 1278/1999 que regulamenta o implante coclear: um estudo no hospital universitário de Brasília. [monografia]. Brasília: Universidade de Brasília; 2012.

Green K. The role of active middle-ear implants in the rehabilitation of hearing loss. Expert Review of Medical Devices. 2011; 8(4):441-7. http://dx.doi.org/10.1586/erd.11.18

Guyton AC, Hall J. Textbook of medical physiology. Philadelphia: Elsevier Saunders; 2006.

Hamacher V, Chalupper J, Eggers J, Fischer E, Kornagel U, Puder H, Rass U. Signal processing in high-end hearing aids: state of the art, challenges, and future trends. EURASIP Journal on Applied Signal Processing. 2005; 18:2915-29. http://dx.doi.org/10.1155/ASP.2005.2915

Haynes DS, Young JA, Wanna GB, Glasscock ME. Middle ear implantable hearing devices: an overview. Trends in amplification. 2009; 13(3):206-14. http://dx.doi. org/10.1177/1084713809346262

Heiduschka P, Thanos S. Implantable bioelectronic interfaces for lost nerve functions. Progress in neurobiology. 1998; 55(5):433-61. http://dx.doi.org/10.1016/ S0301-0082(98)00013-6

Hilú MRPB, Zeigelboim BS. The knowledge and valorization of neonatal auditory screening and the early intervention of hearing loss. Speech, Language, Hearing Sciences and Education Journal. 2007; 9(4):563-70.

Hochmair I, Nopp P, Jolly C, Schmidt M, Schôsser H, Garnham C, Anderson I. Med-el cochlear implants: State of the art and a glimpse into the future. Trends in amplification. 2006; 10(4):201-9. http://dx.doi. org/10.1177/1084713806296720

Hoesel R. Exploring the benefits of bilateral cochlear implants. Audiology and Neurotology. 2004; 9(4):234-46. http://dx.doi.org/10.1159/000078393

Holt R, Svirsky M. An exploratory look at pediatric cochlear implantation: is earliest always best? Ear and hearing. 2008; 29(4):492-511. http://dx.doi.org/10.1097/ AUD.0b013e31816c409f

Honeycutt A, Dunlap L, Chen H, al Homsi G, Grosse S, Schendel D. Economic costs associated with mental retardation, cerebral palsy, hearing loss, and vision impairment - United States, 2003. CDC Morbidity and Mortality Weekly Report. 2004; 53(3):57-9.

Instituto Brasileiro de Geografia e Estatística - IBGE. Censo demográfico 2010: Características gerais da população, religião e pessoas com deficiência [Internet]. Rio de Janeiro: IBGE; 2010. [acesso em 2013 jan 02]. Disponível em: http:// www.ibge.gov.br/home/estatistica/populacao/censo2010/ caracteristicas_religiao_deficiencia/caracteristicas_religiao_ deficiencia_tab_xls.shtm.

Ilberg C, Baumann U, Kiefer J, Tillein J, Adunka O. Electricacoustic stimulation of the auditory system: a review of the first decade. Audiology and Neurotology. 2011; 16(2):1-30. http://dx.doi.org/10.1159/000327765

Izzo AD, Suh E, Pathria J, Walsh JT, Whitlon DS, Richter CP. Selectivity of neural stimulation in the auditory system: a comparison of optic and electric stimuli. Journal of biomedical optics. 2007; 12(2):021008. http://dx.doi. org/10.1117/1.2714296

Kam S, Chi A, Ng I, Cheng M, Wong T, Tong M. Evaluation of the clearvoice strategy in adults using hiresolution fidelity 120 sound processing. Clinical and Experimental Otorhinolaryngology. 2012; 5(1):S89-92. http://dx.doi. org/10.3342/ceo.2012.5.S1.S89

Kasic JF, Fredrickson JM. The otologics met ossicular stimulator. Otolaryngologic Clinics of North America. 2001; 34(2):501-13. http://dx.doi.org/10.1016/ S0030-6665(05)70345-5

Kiefer J, Pok M, Adunka O, Stürzebecher E, Baumgartner W, Schmidt M, Tillein J, Ye Q, Gstoettner W. Combined electric and acoustic stimulation of the auditory system: results of a clinical study. Audiology and Neurotology. 2005; 10(3):134-44. http://dx.doi. org/10.1159/000084023

Ko WH, Zhang R, Huang P, Guo J, Ye X, Young DJ, Megerian CA. Studies of mems acoustic sensors as implantable microphones for totally implantable hearingaid systems. Biomedical Circuits and Systems, IEEE Transactions on. 2009; 3(5):277-85. http://dx.doi.org/10.1109/ TBCAS.2009.2032267 
Kollmeier B, Riedel H, Mauermann M, Uppenkamp S. Physiological measures of auditory function. In: Handbook of Signal Processing in Acoustics. New York: Springer; 2009. p. 159-173.

Kong Y, Stickney G, Zeng F. Speech and melody recognition in binaurally combined acoustic and electric hearing. The Journal of the Acoustical Society of America. 2005; 117(3 Pt 1):1351-61. http://dx.doi.org/10.1121/1.1857526

Kwon B, van den Honert C. Effect of electrode configuration on psychophysical forward masking in cochlear implant listeners. The Journal of the Acoustical Society of America. 2006; 119(5):2994-3002. http://dx.doi. org/10.1121/1.2184128

Lalwani AK, Pfister MH. Recent Advances in Otolaryngology: Head and Neck Surgery. New Delhi: Jaypee Brothers Medical Pub; 2012. http://dx.doi.org/10.5005/jp/books/11595

Landsberger D, Srinivasan A. Virtual channel discrimination is improved by current focusing in cochlear implant recipients. Hearing research. 2009; 254(1):34-41. http:// dx.doi.org/10.1016/j.heares.2009.04.007

Limb S, McManus M, Fox H, White K, Forsman I. Ensuring financial access to hearing aids for infants and young children. Pediatrics. 2010; 126(1):43-51. http://dx.doi.org/10.1542/ peds.2010-0354I

Loizou P. Mimicking the human ear. IEEE Signal Processing Magazine. 1998; 15(5):101-30.

Lorens A, Zgoda M, Obrycka A, Skarżynski H. Fine structure processing improves speech perception as well as objective and subjective benefits in pediatric medel combi $40+$ users. International Journal of Pediatric Otorhinolaryngology. 2010; 74(12):1372-78. http://dx.doi. org/10.1016/j.ijporl.2010.09.005

Luo F, Yang J, Pavlovic C, Nehorai A. Adaptive null-forming scheme in digital hearing aids. IEEE Transactions on Signal Processing. 2002; 50(7):1583-90. http://dx.doi.org/10.1109/ TSP.2002.1011199

Magalhães AMM, Pérez-Ramos AM, Neme CMB, Yamada MO. Desenvolvimento socioemocional de crianças surdas com implante coclear. Boletim-Academia Paulista de Psicologia. 2007; 27(2):103-32.

Mathers C, Fat DM, Boerma J. The global burden of disease: 2004 update. Geneva: WHO; 2008.

Matsuki H, Yamakata Y, Jinguji N, Nitta S, Hoshimiya N, Chubachi N. Energy transferring system reducing temperature rise for implantable power consuming devices. In: Annual International Conference of the IEEE Engineering in Medicine and Biology Society, 1996. Bridging Disciplines for Biomedicine: Proceedings of the 18th Annual International Conference of the IEEE Engineering in Medicine and Biology Society, 1996. Bridging Disciplines for Biomedicine; 1996; Amsterdam. Amsterdam: IEEE; 1996. p. 185-86. http:// dx.doi.org/10.1109/IEMBS.1996.656908

McKay C, Henshall K. Frequency-to-electrode allocation and speech perception with cochlear implants. The Journal of the Acoustical Society of America. 2002; 111(2):1036-44. http://dx.doi.org/10.1121/1.1436073

MED-EL. Med-el announces fda approval of first single-unit audio processor for cochlear implants [Internet]. Vienna: Med-el; 2012a. [acesso em 2013 jan 16]. Disponível em:
http://www.medel.com/data/editor/file/press_releases_US/ RONDO-FDA-Approval-Press-Release-11-09-12.pdf.

MED-EL. News room [Internet]. Vienna: Med-el; 2012b. [acesso em 2013 jan 02]. Disponível em: http://www.medel. com/us/news-room-us/.

Miller CA, Brown CJ, Abbas PJ, Chi SL. The clinical application of potentials evoked from the peripheral auditory system. Hearing research. 2008; 242(1):184-97. http:// dx.doi.org/10.1016/j.heares.2008.04.005

Miller CA, Robinson BK, Rubinstein JT, Abbas PJ, Runge-Samuelson CL. Auditory nerve responses to monophasic and biphasic electric stimuli. Hearing research. 2001; 151(1):79-94. http://dx.doi.org/10.1016/ S0300-2977(00)00082-6

Mohr P, Feldman J, Dunbar J, McConkey-Robbins A, Niparko J, Rittenhouse R, Skinner M. The societal costs of severe to profound hearing loss in the united states. International journal of technology assessment in health care. $2000 ; 16(4): 1120-35$. http://dx.doi.org/10.1017/ S0266462300103162

Moore B. The role of temporal fine structure processing in pitch perception, masking, and speech perception for normal-hearing and hearing-impaired people. Journal of the Association for Research in Otolaryngology. 2008; 9(4):399-406. http:// dx.doi.org/10.1007/s10162-008-0143-x

Morton C, Nance W. Newborn hearing screening-a silent revolution. New England Journal of Medicine. 2006. 354(20):2151-64. http://dx.doi.org/10.1056/ NEJMra050700

Most T. The effects of degree and type of hearing loss on children's performance in class. Deafness \& Education International. 2004; 6(3):154-66.

Mussa C, Kioroglo PS, Bruscato WL, Iervolino SMS, Campos CAH. A atuação do psicólogo durante o processo de implante coclear: relato de caso. Pediatria Moderna. 2010; 46(1):26-30.

National Institute on Deafness and Other Communication Disorders - NIDCD. Fact sheet: Cochlear implants. NIH 11, p.4798 [Internet]. Bethesda: NIDCD; 2011. [acesso em 2013 jan 08]. Disponível em: http://www.nidcd.nih.gov/health/ hearing/coch.asp.

National Institute for Health - NHS. Cochlear implants for children and adults with severe to profound deafness. London: National Institute for Health and Clinical Excellence - NICE; 2009.

Nicholas JG, Geers AE. Effects of early experience on the spoken language of deaf children at 3 years of age. Ear and Hearing. 2006; 27(3):286-98. http://dx.doi.org/10.1097/01. aud.0000215973.76912.c6

Oshima K, Suchert S, Blevins N, Heller S. Curing hearing loss: Patient expectations, health care practitioners, and basic science. Journal of communication disorders. 2010; 43(4):311-18. http://dx.doi.org/10.1016/j.jcomdis.2010.04.002

Patrick J, Busby P, Gibson P. The development of the nucleus $^{\circledR}$ freedom ${ }^{\mathrm{TM}}$ cochlear implant system. Trends in amplification. 2006 10(4):175-200. http://dx.doi. org/10.1177/1084713806296386

Petição Pública. Abaixo-assinado manutenção do implante coclear pelo programa nacional de saúde auditiva/sus [Internet]. Brasil: Petição Pública; 2013. [acesso em 2013 
jan 02]. Disponível em: http://www.peticaopublica.com. $\mathrm{br} /$ ?pi=P2012N18979.

Potts LG, Skinner MW, Gotter BD, Strube MJ, Brenner CA. Relation between neural response telemetry thresholds, t-and c-levels, and loudness judgments in 12 adult nucleus 24 cochlear implant recipients. Ear and Hearing. 2007; 28(4):495511. http://dx.doi.org/10.1097/AUD.0b013e31806dc16e

Ramsden JD, Gordon K, Aschendorff A, Borucki L, Bunne M, Burdo S, Garabedian N, Grolman W, Irving R, Lesinski-Schiedat A.. European bilateral pediatric cochlear implant forum consensus statement. Otology \& Neurotology. 2012; 33(4):561-5. http://dx.doi.org/10.1097/ MAO.0b013e3182536ae2

Richter CP, Bayon R, Izzo AD, Otting M, Suh E, Goyal S, Hotaling J, Walsh JT. Optical stimulation of auditory neurons: effects of acute and chronic deafening. Hearing research. 2008; 242(1):42-51. http://dx.doi.org/10.1016/j. heares.2008.01.011

Robertson L, Flexer C. Reading development: A parent survey of children with hearing impairment who developed speech and language through the auditory-verbal method. Volta Review. 1993; 95(3):253-61. http://dx.doi.org/10.3766/ jaaa.23.5.5

Robinson E, Davidson L, Uchanski R, Brenner C, Geers A. A longitudinal study of speech perception skills and device characteristics of adolescent cochlear implant users. Journal of the American Academy of Audiology. 2012; 23(5):341-9. http://dx.doi.org/10.3766/jaaa.23.5.5

Roland JT Jr. Cochlear implant electrode insertion. Operative Techniques in Otolaryngology-Head and Neck Surgery. 2005; 16(2):86-92. http://dx.doi.org/10.1016/j. otot.2005.04.001

Russ S, White K, Dougherty D, Forsman I. Preface: newborn hearing screening in the united states: historical perspective and future directions. Pediatrics. 2010 126(1):S3-6. http:// dx.doi.org/10.1542/peds.2010-0354D

Sarpeshkar R, Salthouse C, Sit JJ, Baker M, Zhak S, Lu, TT, Turicchia L, Balster S. An ultra-low-power programmable analog bionic ear processor. IEEE Transactions on Biomedical Engineering. 2005; 52(4):711-27. http://dx.doi.org/10.1109/ TBME.2005.844043

Sawigun C, Ngamkham W, Serdijn W. An ultra low-power peak-instant detector for a peak picking cochlear implant processor. In: Biomedical Circuits and Systems Conference (BioCAS), 2010 IEEE. Proceedings of the IEEE BioCAS; 2010 Nov 3-5; Paphos, Cyprus. 2010. p. 222-5

Schatzer R, Krenmayr A, Au D, Kals M, Zierhofer C. Temporal fine structure in cochlear implants: preliminary speech perception results in cantonese-speaking implant users. Acta Oto-Laryngologica. 2010; 130(9):1031-9. http:// dx.doi.org/10.3109/00016481003591731

Sharma A, Dorman M, Spahr A. A sensitive period for the development of the central auditory system in children with cochlear implants: implications for age of implantation. Ear and Hearing. 2002; 23(6):532-9. http:// dx.doi.org/10.1097/00003446-200212000-00004

Shepherd R, Clark G, Black R. Chronic electrical stimulation of the auditory nerve in cats. Acta OtoLaryngologica. 1983; 95(S399):19-31. http://dx.doi. org/10.3109/00016488309105589
Shepherd RK, Linahan N, Xu J, Clark GM, Araki S. Chronic electrical stimulation of the auditory nerve using non-chargebalanced stimuli. Acta Oto-Laryngologica. 1999; 119(6):67484. http://dx.doi.org/10.1080/00016489950180621

Shield B. Evaluation of the social and economic costs of hearing impairment. A report for Hear-it. Bridget Shield: AISBL; 2006.

Skarzynski H, Lorens A, Matusiak M, Porowski M, Skarzynski P, James C. Partial deafness treatment with the nucleus straight research array cochlear implant. Audiology and Neurotology. 2012; 17(2):82-91. http:// dx.doi.org/10.1159/000329366

Skinner M, Clark G, Whitford L, Seligman P, Staller S, Shipp D, Shallop J, Everingham C, Menapace C, Arndt P. Evaluation of a new spectral peak coding strategy for the nucleus 22 channel cochlear implant system. American Journal of Otology. 1994; 15(Suppl 2):15-27.

Skinner MW, Arndt PL, Staller SJ. Nucleus (r) 24 advanced encoder conversion study: Performance versus preference. Ear and Hearing. 2002; 23(1):2S-17S. http://dx.doi. org/10.1097/00003446-200202001-00002

Smith Z, Delgutte B, Oxenham A. Chimaeric sounds reveal dichotomies in auditory perception. Nature. 2002; 416:8790. http://dx.doi.org/10.1038/416087a

Sokol J, Hyde M. Hearing screening. Pediatrics in Review. 2002; 23(5):155-62. http://dx.doi.org/10.1542/ pir.23-5-155

Somek B, Fajt S, Dembitz A, Ivkoviç M, Ostojiç J. Coding strategies for cochlear implants. AUTOMATIKA: Journal for Control, Measurement, Electronics, Computing and Communications. 2006; 47(1-2):69-74.

Summerfield AQ, Barton G. Getting acceptable value for money from bilateral cochlear implantation. Cochlear Implants International. 2003; 4(1):66-7. http://dx.doi. org/10.1002/cii.112

Svirsky M, Teoh S, Neuburger H. Development of language and speech perception in congenitally, profoundly deaf children as a function of age at cochlear implantation. Audiology and Neurotology. 2004; 9(4):224-33. http:// dx.doi.org/10.1159/000078392

Teagle H, Moore J. School-based services for children with cochlear implants. Language, Speech, and Hearing Services in Schools. 2002; 33(3):162-71. http://dx.doi. org/10.1044/0161-1461(2002/014)

Thiemann J. Acoustic noise suppression for speech signals using auditory masking effects [tese]. Montreal: McGill University; 2001.

Tung CY, Chao KP. Effect of recreational noise exposure on hearing impairment among teenage students. Research in Developmental Disabilities. 2013; 34(1):126-32. http:// dx.doi.org/10.1016/j.ridd.2012.07.015

Vermeire K, Kleine Punte A, Van de Heyning P. Better speech recognition in noise with the fine structure processing coding strategy. Journal for Oto-Rhino-Laryngology and its Related Specialties. 2010; 72(6):305-11. http://dx.doi. org/10.1159/000319748

Vogel I, Brug J, Van der Ploeg CP, Raat H. Adolescents risky mp3-player listening and its psychosocial correlates. 
Health Education Research. 2011; 26(2):254-64. http:// dx.doi.org/10.1093/her/cyq091

Vondrasek M, Sovka P, Tichy T. Ace strategy with virtual channels. Radioengineering. 2008; 17(4):55-61.

Wallace G, Moulton S, Clark G. Applied physics: Electrodecellular interface. Science. 2009; 324:185-6. http://dx.doi. org/10.1126/science. 1168346

Wang Z, Mai S, Zhang C. Power issues on circuit design for cochlear implants. In: DELTA 2008: Proceedigns of the 4th IEEE International Symposium on Electronic Design, Test and Applications; 2008; Hong Kong. Hong Kong: IEEE; 2008. p. 163-6. http://dx.doi.org/10.1109/ DELTA. 2008.13

Wells J, Kao C, Konrad P, Mahadevan-Jansen A, Jansen E D. Biophysical mechanisms responsible for pulsed low-level laser excitation of neural tissue. In: Biomedical Optics. International Society for Optics and Photonics; 2006. p. $60840 \mathrm{X}$.

Wenzel G, Balster S, Lim H, Zhang K, Reich U, Lubatschowski H, Ertmer W, Lenarz T, Reuter G. Stimulation of the cochlea using green laser light. Journal of Biomedical Optics. 2009; 14(4):044007. http://dx.doi. org/10.1117/1.3174389

Wilson B, Finley C, Lawson D, Wolford R, Zerbi M. Design and evaluation of a continuous interleaved sampling (cis) processing strategy for multichannel cochlear implants. Journal of Rehabilitation Research and Development. 1993; 30(1):110-6.

Wilson BS, Dorman MF. Cochlear implants: current designs and future possibilities. Journal of Rehabilitation Research and Development. 2008; 45(5):695-730. http://dx.doi. org/10.1682/JRRD.2007.10.0173

Wolf-Magele A, Schnabl J, Woellner T, Koci V, Riechelmann $\mathrm{H}$, Sprinzl GM. Active middle ear implantation in elderly people: a retrospective study. Otology \& Neurotology. 2011; 32(5):805-11. http://dx.doi.org/10.1097/ MAO.0b013e31821a41ba

World Health Organization - WHO. Deafness and hearing impairment. Fact sheet $\mathrm{N}^{\circ} 300$ [Internet]. Genebra: WHO; 2012. [acesso em 2013 nov 30]. Disponível em: http:// www.who.int/mediacentre/factsheets/fs300/en/index.html.
World Health Organization - WHO. Grades of hearing impairment [Internet]. Genebra: WHO; 2013a. [acesso em 2013 jan 30]. Disponível em: http://www.who.int/ $\mathrm{pbd} /$ deafness/hearing_impairment_grades/en/index.html.

World Health Organization - WHO. Who global estimates on prevalence of hearing loss [Internet]. Genebra: WHO; 2013b. [acesso em 2013 jan 02]. Disponível em: http://www.who. int/pbd/deafness/estimates/en/index.html.

$\mathrm{Xu}$ L, Pfingst B. Spectral and temporal cues for speech recognition: Implications for auditory prostheses. Hearing Research. 2008; 242(1-2):132-40. http://dx.doi.org/10.1016/j. heares.2007.12.010

Yoshinaga-Itano C, Apuzzo ML. Identification of hearing loss after 18 months of age is not early enough. American Annals of the Deaf. 1998; 143(3):380-7. http://dx.doi. org/10.1353/aad.2012.0151

Yoshinaga-Itano C, Sedey A, Coulter D, Mehl A. Language of early-and later-identified children with hearing loss. Pediatrics. 1998; 102(5):1161-71. http://dx.doi.org/10.1542/ peds.102.5.1161

Young DJ, Zurcher MA, Ko WH, Semaan M, Megerian CA. Implantable mems accelerometer microphone for cochlear prosthesis. EEE International Symposium on Circuits and Systems. 2007; 3119-3122.

Zeng F. Trends in cochlear implants. Trends in Amplification. 2004; 8(1):1-34. http://dx.doi. org/10.1177/108471380400800102

Zeng F, Grant G, Niparko J, Galvin J, Shannon R, Opie J, Segel P. Speech dynamic range and its effect on cochlear implant performance. Journal of the Acoustical Society of America. 2002; 111(1 Pt 1):377-86. http://dx.doi. org/10.1121/1.1423926

Zeng F, Rebscher S, Harrison W, Sun X, Feng H. Cochlear implants: System design, integration, and evaluation. IEEE Reviews in Biomedical Engineering,. 2008; 1:115-42. http:// dx.doi.org/10.1109/RBME.2008.2008250

Zwolan TA, Griffin BL. How we do it: tips for programming the speech processor of an 18-month-old. Cochlear implants international. 2005; 6(4):169-77. http://dx.doi.org/10.1002/cii.9

\begin{abstract}
Autores
Diego Tefili, Djones Vinicius Lettnin

Embedded System Group, Departamento de Engenharia Elétrica, Universidade Federal de Santa Catarina - UFSC, Campus Universitário Reitor João David Ferreira Lima, Bairro Trindade, CEP 88040-900, Florianópolis, SC, Brasil.
\end{abstract}

Diego Tefili, Guillaume François Gilbert Barrault*, Alexandre André Ferreira

WaveTech Soluções Tecnológicas, Parque Tecnológico Alfa, Edifício CELTA, Rod. SC 401, Km 01, Bairro João Paulo, CEP 88030-000, Florianópolis, SC, Brasil.

Guillaume François Gilbert Barrault*, Júlio Apolinário Cordioli

Laboratório de Vibrações e Acústica, Departamento de Engenharia Mecânica, Universidade Federal de Santa Catarina - UFSC, Campus Universitário Reitor João David Ferreira Lima, Bairro Trindade, CEP 88040-900, Florianópolis, SC, Brasil. 